FEDERAL RESERVE BANK OF SAN FRANCISCO

WORKING PAPER SERIES

\title{
Welfare-Maximizing Monetary Policy under Parameter Uncertainty
}

\author{
Rochelle M. Edge \\ Board of Governors of the Federal Reserve System \\ Thomas Laubach \\ Board of Governors of the Federal Reserve System \\ John C. Williams \\ Federal Reserve Bank of San Francisco
}

May 2008

Working Paper 2007-11

http://www.frbsf.org/publications/economics/papers/2007/wp07-11bk.pdf

\begin{abstract}
The views in this paper are solely the responsibility of the authors and should not be interpreted as reflecting the views of the Federal Reserve Bank of San Francisco or the Board of Governors of the Federal Reserve System.
\end{abstract}




\title{
Welfare-Maximizing Monetary Policy under Parameter Uncertainty
}

\author{
Rochelle M. Edge, Thomas Laubach, and John C. Williams *
}

May 30, 2008

\begin{abstract}
This paper examines welfare-maximizing monetary policy in an estimated micro-founded general equilibrium model of the U.S. economy where the policymaker faces uncertainty about model parameters. Uncertainty about parameters describing preferences and technology implies uncertainty about the model's dynamics, utility-based welfare criterion, and the "natural" rates of output and interest that would prevail absent nominal rigidities. We estimate the degree of uncertainty regarding natural rates due to parameter uncertainty. We find that optimal Taylor rules under parameter uncertainty respond less to the output gap and more to price inflation than would be optimal absent parameter uncertainty. We also show that policy rules that focus solely on stabilizing wages and prices yield welfare outcomes very close to the first-best.
\end{abstract}

JEL Code: E5

Keywords: technology shocks, monetary policy rules, natural rate of output, natural rate of interest.

*Board of Governors of the Federal Reserve System, rochelle.m.edge@frb.gov; Goethe University Frankfurt, laubach@wiwi.uni-frankfurt.de; and Federal Reserve Bank of San Francisco, john.c.williams@sf.frb.org (corresponding author). We thank Richard Dennis, Petra Geraats, Andy Levin, Bruce Preston, Chris Sims, Ulf Söderström, Shaun Vahey, two anonymous referees, and participants at the Federal Reserve Bank of San Francisco Conference on "Monetary Policy, Transparency, and Credibility," the Reserve Bank of Australia Conference on "Monetary Policy in Open Economies," and seminars at the European Central Bank, Humboldt Universität Berlin, and the Federal Reserve Board for valuable comments. The views expressed herein are those of the authors and do not necessarily reflect those of the Board of Governors of the Federal Reserve System, its staff, or the management of the Federal Reserve Bank of San Francisco. 


\section{Introduction}

This paper examines welfare-maximizing monetary policy in an estimated dynamic stochastic general equilibrium (DSGE) model of the U.S. economy where the central bank faces uncertainty about the values of model parameters. The design of optimal monetary policy depends on the nature of the dynamics of the economy, the natural rates of output and interest, and the central bank objective function. Traditional analysis of monetary policy under uncertainty has treated these three factors as independent and studied them in isolation (see, for example, Brainard 1967, and Rudebusch 2001). But, modern micro-founded models imply that the structural parameters describing preferences and technology jointly determine all three factors. Therefore, an analysis of monetary policy under parameter uncertainty requires that these consequences of parameter uncertainty be analyzed in unison.

Recent papers by Giannoni (2002), Levin and Williams (2005), and Levin, Onatski, Williams and Williams (2005; henceforth LOWW), have studied monetary policy under parameter uncertainty in micro-founded models. The latter two papers imposed the linkage between parameter uncertainty and uncertainty about the welfare costs of fluctuations, but neither examined the role of natural rate uncertainty in the design of optimal policy. Aoki and Nikolov (2004) highlighted the connection between parameter uncertainty and uncertainty about the natural rate of interest - defined to be the real interest rate that would prevail absent nominal rigidities - but did not explore further the role of natural rates in the design of optimal policy under uncertainty.

We use a small estimated micro-founded model as a laboratory to explore how parameter uncertainty and the associated uncertainty about natural rates and welfare costs of fluctuations affects the design of optimal monetary policy. We use the estimated covariance of model parameters as a measure of parameter uncertainty. We analyze the implications of parameter uncertainty on policy design and outcomes, from the perspective of a Bayesian policymaker who aims to maximize expected household welfare. We first show that parameter uncertainty implies a non-trivial degree of uncertainty about the natural rates of output and interest and that natural rate misperceptions on the part of the central bank are likely to be persistent. We then show that optimal Taylor rules under parameter uncertainty respond less to the output gap and more to price inflation than would be optimal absent

parameter uncertainty. This conclusion is consistent with that found in the literature on optimal Taylor (1993) rules using traditional models, despite the very different analytical 
frameworks (see Orphanides and Williams, 2002, and references therein). Finally, we show that policy rules that respond solely to wage and price inflation perform better than the optimized Taylor rule and yield welfare outcomes very close to the first-best.

The remainder of the paper is organized as follows. Section 2 describes the model that we use for our analysis. Section 3 describes the model estimation and reports the results. Section 4 examines optimal monetary policy assuming model parameters are known. Section 5 considers optimal policy under parameter uncertainty. Section 6 reexamines the design of optimal policy using an alternative model of nominal rigidities. Section 7 concludes.

\section{The Model}

Our analysis uses a small micro-founded model with various frictions that interfere with instantaneous full adjustment of quantities and prices to shocks. To make the analysis tractable, we abstract from many features present in recently developed larger DSGE models, such as investment, fiscal policy, and international trade (see, for example, Christiano, Eichenbaum, and Evans, 2005, Smets and Wouters, 2003, and Lubik and Schorfheide, 2005). We leave for future work the extension of our analysis to richer models.

We first present the model's preferences and technology and then describe the firms' and households' optimization problems. Mathematical descriptions of these problems are given in Appendix A along with the model's nonlinear and linearized first order conditions and steady-state solution. Throughout, we denote the log of variables by lower case letters.

\subsection{The production technology}

The economy's final good, $Y_{f, t}$, is produced according to the Dixit-Stiglitz technology,

$$
Y_{f, t}=\left(\int_{0}^{1} Y_{f, t}(x)^{\frac{\Theta_{p, t}-1}{\Theta_{p, t}}} d x\right)^{\frac{\Theta_{p, t}}{\Theta_{p, t}-1}}
$$

where $Y_{f, t}(x)$ denotes the quantity of the $x$ th differentiated goods used in production and $\Theta_{p, t}$ is the time-varying elasticity of substitution between the production inputs.

Final goods producers obtain their production inputs from the economy's differentiated intermediate goods producers who supply an output $Y_{m, t}(x)$. Not all of the differentiated output produced by the intermediate goods producers is realized as final goods' inputs; some output is absorbed in price formulation, following the adjustment cost model of Rotemberg 
(1982). We modify the Rotemberg model so that the cost of adjusting prices is relative to a rule of thumb price adjustment equal to a weighted average of steady-state inflation and last period's inflation rate. In this way, we allow for intrinsic inertia in inflation. Specifically, the relationship between $Y_{f, t}(j)$ and $Y_{m, t}(j)$ is given by

$$
Y_{f, t}(j)=Y_{m, t}(j)-\frac{\chi_{p}}{2}\left(\frac{P_{t}(j)}{P_{t-1}(j)}-\left(1-\gamma_{p}\right) \Pi_{p, *}-\gamma_{p} \Pi_{p, t-1}\right)^{2} Y_{m, t}
$$

where the second term in (2) denotes the cost of setting prices, $P_{t}(j)$ is the price charged by firms $j$ for a unit of its output, $\Pi_{p, *}$ is the steady-state price inflation rate, and $\Pi_{p, t-1}$ is the lagged price inflation rate. Our choice of quadratic adjustment costs for modeling nominal rigidities contrasts with that of many other recent studies, which rely instead on staggered contracts as in Calvo (1983). The first-order dynamics of prices and wages are identical to those derived from Calvo-based models. The second-order approximation to welfare, however, differs between the quadratic adjustment cost model and the Calvo-based model and we examine the properties of optimal policies with a Calvo-based model in section 6 .

The differentiated intermediate goods, $Y_{m, t}(j)$ for $j \in[0,1]$, are produced by combining each variety of the economy's differentiated labor inputs that are supplied to market activities (that is, $\left\{L_{y, t}(z)\right\}$ for $z \in[0,1]$ ). The composite bundle of labor, denoted $L_{y, t}$, that obtains from this aggregation implies, given the current level of technology $A_{t}$, the output of the differentiated goods, $Y_{m, t}$. Specifically, production is given by,

$$
Y_{m, t}(j)=A_{t} L_{y, t}(j) \text { where } L_{y, t}(j)=\left(\int_{0}^{1} L_{y, t}(x, j)^{\frac{\Theta_{w, t}-1}{\Theta_{w, t}}} d x\right)^{\frac{\Theta_{w, t}}{\Theta_{w, t}}} .
$$

where $\Theta_{w, t}$ is the time-varying elasticity of substitution between the differentiated labor inputs. The log-level of technology, $A_{t}$, is modeled as a random walk:

$$
\ln A_{t}=\ln A_{t-1}+\epsilon_{A, t}
$$

where $\epsilon_{A, t}$ is an i.i.d. innovation. We abstract from trend growth in productivity.

\section{$2.2 \quad$ Preferences}

Households own shares in the firms in the economy. They derive utility from their purchases of the consumption good $C_{t}$ and from their use of leisure time, equal to what remains of their time endowment $\bar{L}$ after $0 \leq L_{u, t}(i) \leq \bar{L}$ hours of labor are allocated to nonleisure activities. We assume the household members live forever and there is no population 
growth. Household preferences exhibit an additive habit (equal to a fraction $\eta \in[0,1]$ of its consumption last period) and are nonseparable between consumption and leisure. Specifically, preferences of household $i$ are given by

$$
E_{0} \frac{1}{1-\sigma} \sum_{t=0}^{\infty} \beta^{t} \Xi_{c, t}\left[\left(C_{t}(i)-\eta C_{t-1}(i)\right)\left(\bar{L}-L_{u, t}(i)\right)^{\zeta}\right]^{1-\sigma}
$$

where $\beta$ is the household's discount factor and $\Xi_{c, t}$ a stochastic preference shifter that is assumed to follow an AR(1) process in logs. The economy's resource constraint implies that $\int_{0}^{1} C_{t}(x) d x \leq Y_{f, t}$, where $Y_{f, t}$ denotes the output of the economy's final good.

Household $i$ supplies $L_{y, t}(i)$ hours to the labor market and devotes time to setting wages. Consequently, time allocated to non-leisure activities, $L_{u, t}(i)$, is given by

$$
L_{u, t}(i)=L_{y, t}(i)+\frac{\chi_{w}}{2}\left(\frac{W_{t}(i)}{W_{t-1}(i)}-\left(1-\gamma_{w}\right) \Pi_{w, *}-\gamma_{w} \Pi_{w, t-1}\right)^{2} L_{u, t},
$$

where the second term in (6) denotes the cost of setting wages in terms of labor time and is analogous to the cost of setting prices, $W_{t}(i)$ is the wage charged by household $i$ for a unit of its time, $\Pi_{w, *}$ is the steady-state wage inflation rate, and $\Pi_{w, t-1}$ is the lagged wage inflation rate.

\subsection{Firms' optimization problems}

The final goods producing firm takes as given the prices set by each intermediate-goods producer for their differentiated output, $\left\{P_{t}(j)\right\}_{j=0}^{1}$, and chooses intermediate inputs, $\left\{Y_{f, t}(j)\right\}_{j=0}^{1}$, to minimize the cost of producing its final output $Y_{f, t}$, subject to its production technology, given by equation (1).

Each intermediate-goods producing firm chooses the quantities of labor that it employs in production and the price that it will set for its output. In deciding the quantities of the various types of labor to employ, firm $j$ takes as given the wage $\left\{W_{t}(i)\right\}_{i=0}^{1}$ set by each household for its variety of labor and chooses $\left\{L_{y, t}(i, j)\right\}_{i=0}^{1}$ to minimize the cost of attaining the aggregate labor bundle $L_{y, t}(j)$ that it needs for production.

In setting its price, $P_{t}(j)$, the intermediate-goods producing firm takes into account the demand schedule for its output that it faces from the final goods sectors and the fact-as summarized in equation (2) - that its price affects the amount of its output that it can sell to final goods producers. The intermediate-goods producing firm $j$ takes as given the 
marginal cost $M C_{t}$ for producing $Y_{m, t}(j)$, the aggregate price level $P_{t}$, and aggregate finalgoods demand $Y_{f, t}$, and chooses its price $P_{t}(j)$ to maximize the present discounted value of its profits subject to the cost of re-setting its price and the demand curve it faces for its differentiated output. We assume a subsidy on production, equal to $\left(\Theta_{p, *}-1\right)^{-1}$ that offsets the distortionary effects of the presence of the markup of prices over costs due to the presence of monopolistic competition. ${ }^{1}$

\subsection{Households' optimization problem}

The household, taking as given the expected path of the gross nominal interest rate $R_{t}$, the price level $P_{t}$, the aggregate wage rate $W_{t}$, its profits income, and its initial stock of bonds, chooses its consumption $C_{t}(i)$ and its wage $W_{t}(i)$ to maximize its utility subject to its budget constraint, the cost of re-setting its wage, and the demand curve it faces for its differentiated labor. In performing this problem we assume a subsidy on labor supply, equal

to $\left(\Theta_{w, *}-1\right)^{-1}$, which, in combination with the production subsidy described above, ensures that in the absence of nominal rigidities the model's equilibrium outcome is Pareto optimal. The model's subsidies on labor supply and production are funded by lump sum taxes that are imposed on households by the fiscal authority (which operates in the background of our model) solely to finance these subsidies.

\subsection{Steady-state and natural rate variables}

The non-stochastic steady state is summarized by the steady-state levels of the real interest rate and hours. The steady-state one-period real interest rate is given by $R_{*}=\beta^{-1}$ while the steady-state level of hours is given by $L_{*}=\left(1+\frac{1-\eta}{1-\beta \eta} \zeta\right)^{-1} \bar{L}$. Given the assumed nonstationarity of the level of technology, in the following we work with normalized variables, where we normalize the levels of consumption and output by the current level of technology. The normalized steady-state levels of consumption and output therefore equal the steadystate level of hours.

The model has a counterpart in which all nominal rigidities are absent, that is, prices and wages are fully flexible, that is, $\chi_{p}=\chi_{w}=0$. We refer to the levels of output, hours,

\footnotetext{
${ }^{1}$ We acknowledge that such subsidies do not exist in practice, implying that in the real world the steadystate level of output is inefficient. We leave to future work the study of optimal policy under parameter uncertainty in an economy characterized by a distorted steady-state allocation.
} 
and the real one-period interest rate in this equilibrium as the natural rates of output, $\tilde{Y}_{t}$,

hours, $\widetilde{L}_{t}$, and interest, $\widetilde{R}_{t}$, respectively. We also define $\log$ deviations of these variables from their steady-state values, $\tilde{y}_{t} \equiv \log \widetilde{Y}_{t}-\log Y_{*}$ and $\tilde{r}_{t} \equiv \log \widetilde{R}_{t}-\log R_{*}$. These natural rates are functions of our model's structural shocks and are derived in Appendix A.

\subsection{Monetary authority}

We assume that the central bank uses the short-term interest rate as its instrument, For estimation purposes, we assume that the short-term interest rate responds to deviations of price inflation from its steady-state level, $\pi_{p, t} \equiv \log \Pi_{p, t}-\log \Pi_{p, *}$, and to the output gap, $x_{t}=\log Y_{t}-\log \tilde{Y}_{t}$. We also allow for policy inertia by including the lagged short-term interest rate in the feedback equation. In particular, monetary policy is described by

$$
r_{t}=\phi_{r} r_{t-1}+\left(1-\phi_{r}\right)\left\{\phi_{p} \pi_{p, t}+\phi_{x} x_{t}\right\}+\epsilon_{r, t}
$$

where $r_{t} \equiv \log R_{t}-\log R_{*}, y_{t} \equiv \log Y_{t}-\log Y_{*}$, and $\epsilon_{r, t}$ is an i.i.d. policy shock. Note that we have suppressed the constant that incorporates the steady-state levels of the interest and inflation rate. In the analysis of optimal monetary policy, we specify a generalized version of this policy rule, as described in section 4 .

\subsection{Equilibrium}

Our model consists of the first-order conditions (derived in Appendix A) describing firms' optimal choice of prices and households' optimal choices of consumption and wages, the production technology $(3)$, the policy rule $(7)$, the market clearing conditions $Y_{t}(j)=$ $\int_{0}^{1} C_{j, t}(i) d i \forall j$ and $L_{t}(i)=\int_{0}^{1} L_{i, t}(j) d j \forall i$, and the laws of motion for technology and the preference shock.

\section{Estimation}

In order to analyze optimal Bayesian monetary policy under parameter uncertainty, we need a posterior distribution of the model parameters. One approach to obtaining a posterior distribution, consistent with the Bayesian approach to decision-making we assume for the policymaker, is to estimate the model using Bayesian methods, as in LOWW and Justiniano and Preston (this volume). This approach necessitates making specific assumptions regarding the prior joint distribution of the model parameters. Because we want to avoid having 
the choice of the prior distribution overly influence our results, we instead follow a limitedinformation approach to estimating the posterior distribution of the model parameters. ${ }^{2}$ In particular, we estimate several of the structural parameters of our model using a minimum distance estimation based on impulse responses to monetary policy and technology shocks.

Specifically, we estimate a VAR on quarterly U.S. data using empirical counterparts to the theoretical variables in our model, and identify two of the model's structural shocks using identifying assumptions that are motivated by our theoretical model. We then choose model parameters to match as closely as possible the impulse responses to these two shocks implied by the model to those implied by an structural VAR. ${ }^{3}$ In this section we first describe the VAR and the identification of the two shocks, and then discuss our parameter estimates.

\subsection{VAR specification and identification}

The specification of our VAR is determined by the model developed in the previous section and our identification strategy for the structural shocks. Concerning the latter, we follow Galí (1999) and assume that the technology shock is the only shock that has a permanent effect on the level of output per hour. The monetary shock is identified by the restriction that the last variable in the VAR (the funds rate) is Wold-causal for the preceding variables. Our model and identifying assumptions combined suggest the inclusion of five variables in the VAR: the first difference of log output per hour, price inflation (the first difference of the log of the GDP deflator), the log labor share, the first difference of log hours per person, and the nominal funds rate. Output per hour, the labor share, and hours are the Bureau of Labor Statistics' (BLS) measures for the nonfarm business sector, where the labor share is computed as output per hour times the deflator for nonfarm business output divided by compensation per hour. Population is the civilian population age 16 and over. Letting $Y_{t}$ denote the vector of variables in the VAR, we view the data in the VAR as corresponding,

\footnotetext{
${ }^{2}$ For various reasons, our approach may over- or under-estimate the degree of parameter uncertainty that a policymaker faces. The extent to which our estimate of the spread of the posterior distribution is biased should primarily affect the quantitative aspect of out results, not the qualitative nature.

${ }^{3}$ Applications of this estimation strategy are found in Rotemberg and Woodford (1997), Amato and Laubach (2003), and Christiano et al. (2005). This estimation methodology remains the subject of considerable controversy; see e.g. Christiano et al. (2006) and Kehoe (2006).
} 
up to constants, to the model variables

$$
Y_{t}=\left[\Delta\left(y_{t}-l_{t}\right), \pi_{t}, y_{t}-l_{t}-w_{t}, \Delta l_{t}, r_{t}\right]^{\prime}
$$

where lower case letters denote logs of the model variables. We estimate the VAR over the sample 1966q2 to 2006q2, including four lags of each variable.

The structural form of the VAR is given by

$$
A_{0} Y_{t}=\text { constant }+A(L) Y_{t-1}+\varepsilon_{t}
$$

where $Y_{t}$ is defined in (8). The short-run assumption implies that the last column of the contemporaneous multiplier matrix $A_{0}$ has all zeros above the main diagonal. The fifth element of $\varepsilon_{t}$ is identified as the funds rate shock $\epsilon_{r, t}$ in (7). The long-run identifying restriction of Galí (1999) is that permanent shocks to technology are the only shocks to have a permanent effect on labor productivity. Using this assumption, we identify the first element of $\varepsilon_{t}$ as the technology shock $\epsilon_{a, t}$ in (4). This implies that the first row of the matrix of long-run (cumulative) effects of $\varepsilon_{t}$ on $Y_{t},(I-A(1))^{-1} A_{0}^{-1}$, consists of zeros except for the first element. Appendix B provides further details. ${ }^{4}$

The dashed lines in Figure 1 show the impulse responses to a permanent one percent increase in the level of technology. The dashed-dotted lines are one-standard deviation bands around the impulse responses, computed by bootstrap methods. ${ }^{5}$ Figure 2 shows the impulse responses to a one percentage point positive funds rate shock. The responses to a funds rate shock are more precisely estimated than those for the technology shock.

\footnotetext{
${ }^{4} \mathrm{~A}$ potentially controversial aspect of our specification is the inclusion of hours per capita in first differences. Recent years have witnessed a vigorous debate among macroeconomists whether hours worked increase or decline following a technology shock. Francis and Ramey (2005) and Altig et al. (2002) have attributed differences in results among different studies to the issue whether hours per capita are included in levels - in which case the level of hours is usually found to rise immediately following a technology shock - or whether hours enter in first differences or some other detrended form - in which case the level of hours is often found to decline during the first few quarters following the shock. We acknowledge that this is a further important source of parameter uncertainty, but space constraints prevent us from addressing this issue in our analysis.

${ }^{5}$ To prevent the standard error bands from diverging over time, we discard draws for which the implied reduced-form VAR is unstable, such as draws for which the largest eigenvalue of the coefficient matrix in the reduced form, written in companion form, exceeds .99. In total, about 14 percent of draws are rejected.
} 


\subsection{Model parameter estimates}

Before estimating the structural and monetary policy parameters of our model, we calibrate several model parameters that play a small or no role in the model's dynamics. We set the discount factor, $\beta=0.9924$, We normalize the time endowment to unity and set the steadystate rates of price and wage inflation to zero. Because the parameters $\Theta_{w}$ and $\chi_{w}$ and $\Theta_{p}$ and $\chi_{p}$ appear only as a ratio in the linearized version of the model (see Appendix A), they are not separately identified. Following LOWW (2005), we set $\Theta_{w}$ and $\Theta_{p}$ to 6. Given these values, we estimate the coefficients on the driving process in the wage and price Phillips equations, $\kappa_{w}=\Theta_{w} /\left(\chi_{w} \Pi_{w, *}^{2}\right)$ and $\kappa_{p}=\Theta_{p} /\left(\chi_{p} \Pi_{p, *}^{2}\right)$. From these estimates it is possible to compute the implied values for $\chi_{w}$ and $\chi_{p}$, but for convenience we focus on the values of $\kappa_{w}$ and $\kappa_{p}$.

The remaining parameters are estimated by minimizing the squared deviations of the responses of the five variables $\left[y_{t}, \pi_{t}, w_{t}, l_{t}, r_{t}\right]$ implied by our model from their VAR counterparts. ${ }^{6}$ To determine the horizon over which to match the IRFs, we apply the information criterion of Hall et al. (2007), searching over a minimum horizon of quarters 0 through 4 and a maximum horizon of quarters 0 through 16 . This criterion leads us to match the IRFs of the five variables in quarters 0 through 13 following a technology shock in quarter 0 , and in quarters 1 through 13 following a funds rate shock (the response in the impact quarter being constrained by the identifying assumption), for a total of 135 moments to match. These moments are weighted inversely proportional to the standard error around the VAR responses, as in Christiano et al. (2005). This places more weight on matching the impulse responses to the monetary shock, which, as noted before, are estimated with greater precision than the impulse responses to the technology shock.

When we estimate the model using the policy rule (7), we find a slightly negative, but near zero, response of monetary policy to the output gap, perhaps because the model's notion of the output gap bears little resemblance to measures used by policymakers. We therefore restrict $\phi_{x}$ to zero. We impose the restriction that $\phi_{p}>1$, which is a necessary

\footnotetext{
${ }^{6}$ Specifically, we first cumulate the VAR's IRFs of $\Delta\left(y_{t}-l_{t}\right)$ and $\Delta l_{t}$ to obtain the IRFs of $y_{t}-l_{t}$ and $l_{t}$, and then add the latter to the former to obtain the IRF of $y_{t}$. We also subtract the IRF of $y_{t}-l_{t}-w_{t}$ from the IRF of $y_{t}-l_{t}$ to obtain the IRF of $w_{t}$. Since our VAR includes a constant in each equation, but allows for permanent shocks to the levels of output, output per hour and the real wage, these levels follow a unit root process with deterministic drift. The IRFs to a technology shock are therefore interpreted as the permanent percent deviation from their growth path that would have obtained had the shock not occurred.
} 
Table 1: Parameter Estimates

\begin{tabular}{lcccccccc}
\hline \hline \multirow{2}{*}{ Model } & Point & Standard & \multicolumn{5}{c}{ Correlation with } \\
\cline { 5 - 9 } Parameter & Estimate & Error & & \multicolumn{1}{c}{$\eta$} & \multicolumn{1}{c}{$\zeta$} & \multicolumn{1}{c}{$\kappa_{w}$} & \multicolumn{1}{c}{$\kappa_{p}$} \\
\hline$\sigma$ & 8.209 & 2.609 & & 1.000 & -0.995 & 0.996 & 0.716 & 0.008 \\
$\eta$ & 0.364 & 0.070 & & 1.000 & -0.986 & -0.700 & -0.019 \\
$\zeta$ & 1.740 & 0.179 & & & 1.00 & 0.731 & 0.019 \\
$\kappa_{w}$ & 0.006 & 0.000 & & & & 1.000 & -0.156 \\
$\kappa_{p}$ & 0.010 & 0.000 & & & & & 1.000 \\
\hline$\phi_{r}$ & 0.840 & 0.001 & & & & & \\
$\phi_{p}$ & 1.000 & 0.019 & & & & & \\
\hline \hline
\end{tabular}

condition for determinacy in our model. ${ }^{7}$ Furthermore, unrestricted estimation leads to estimates of the indexation parameters $\gamma_{w}$ and $\gamma_{p}$ very close to or at the upper limit of $1 .^{8}$ Because our method of examining parameter uncertainty described below becomes infeasible when parameters are at boundaries, in the remainder we fix both of these two parameters at 1 . In the end, we therefore estimated the seven parameters $\left\{\sigma, \zeta, \eta, \kappa_{w}, \kappa_{p}, \phi_{r}, \phi_{p}\right\}$.

The estimated parameters and associated standard errors are shown in the first two columns of Table 1. The correlation coefficients of the structural parameter estimates are shown in the final five columns of the table. The covariance matrix of the estimates is computed using the Jacobian matrix from the numerical optimization routine and the empirical estimate of the covariance matrix of the impulse responses from the bootstrap. The estimates of the structural parameters are all statistically significant. The parameters associated with wage and price adjustment costs are estimated with a great deal of precision. In contrast, the preference parameters, especially $\sigma$ and $\zeta$, are relatively imprecisely estimated and the estimates are very highly correlated with each other, reflecting the difficulty the data have in separating the influences of these parameters. We analyze this issue below.

The VAR responses of real wages and inflation differ substantially depending on the

\footnotetext{
${ }^{7}$ An alternative specification would be to impose the estimated policy rule implied by the VAR, as in Rotemberg and Woodford (1997). This reduces the number of parameters to be estimated, but can lead to convergence problems if the VAR rule and some constellation of structural parameters leads to indeterminacy.

${ }^{8}$ Estimates of $\gamma_{w}$ and $\gamma_{p}$ are sensitive to the horizon of the IRFs that we match. Matching IRFs of quarters 0 through 4 or 0 through 5 , imply $\gamma_{w}$ and $\gamma_{p}$ estimates close to 0 ; for longer horizons $\gamma_{w}$ and $\gamma_{p}$ are at or near 1 . The information criterion strongly suggests matching IRFs of quarters 0 through 12 or longer.
} 
source of the shock: with rapid responses to technology shocks, and sluggish ones to funds rate shocks. This is a feature that our price and wage specification cannot deliver. Our estimates of $\kappa_{w}$ and $\kappa_{p}$ imply that wages are very slow to adjust, while prices adjust more quickly to fundamentals. These results are driven by the IRFs to the technology shock; indeed, the IRFs to monetary policy shocks alone suggest very gradual price adjustment, consistent with Christiano et al (2005). Despite the greater weight placed on matching the more tightly estimated responses of inflation and real wage to the funds rate shock, our model does better at matching the responses to a technology shock, as shown by the solid lines in Figures 1 and 2. Our estimates of the parameters of the monetary policy rule, $\phi_{r}$ and $\phi_{\pi}$, are broadly consistent with the findings of many other studies that estimate monetary policy reaction functions, such as that of Clarida, Galí, and Gertler (2000).

One concern with the estimation of structural parameters in DSGE models in general, and the method of IRF matching in particular, is parameter identification (Canova and Sala, 2006, Iskrev, 2007). In our case, we are particularly concerned about the separate identification of the preference parameters $\sigma$ and $\zeta$, and the adjustment cost parameters $\kappa_{w}$ and $\kappa_{p}$. We illustrate the potential for weak identification of each of these two pairs in Figure 3 by plotting the negative of the objective function while varying two of the parameters within a range around their final estimates, holding all other parameters fixed at their estimated values. The upper panel of Figure 3 shows that the objective function is fairly flat for values of $\sigma$ above 8, regardless of the value of $\zeta$. The lower panel of the figure shows that, conditional on $\kappa_{p}$ being at its estimated value of $0.01, \kappa_{w}$ is poorly identified anywhere between 0.004 and 0.01 . These figures thus underline the substantial degree of ignorance about the true values of the parameters, which, if anything, our standard errors based on the Jacobian seem to be understating.

\section{Welfare and Optimal Monetary Policy}

In this section we compute the optimal monetary policy responses to technology and preferences shock assuming all model parameters are known. We assume that the central bank objective is to maximize the unconditional expectation of the welfare of the representative household. We further assume that the central bank has the ability to commit to future policy actions; that is, we examine optimal policy under commitment, as opposed to discretion. 
We consider only policies that yield a unique rational expectations equilibrium.

By focussing only on technology and preference shocks, we are admittedly examining only a relatively small source of aggregate fluctuations in output and wage and price inflation and hence welfare losses in our model. Variance decomposition estimates indicate that these two shocks account for only a small share of variations in hours at horizons beyond two years and account for a small share of wage and price variability at all horizons. To conduct welfare-based monetary policy analysis incorporating other sources of fluctuations, we would need to take a stand on the source of the other shocks to the economy. This would take us afield of the primary purpose of the paper, and we therefore leave it to further research.

\subsection{Approximating household welfare}

We approximate household utility with a second-order Taylor expansion around the deterministic steady state following the approach developed by Rotemberg and Woodford (1997) and extended to models with nominal wage rigidities by Erceg, Henderson, and Levin (2000). We denote steady-state values with an asterisk subscript. As shown in Appendix $\mathrm{C}$, the second-order approximation of the period utility function depends on the squared output gap, $x_{t}$, the squared quasi-difference of the output gap, the cross-product of the output gap and its quasi-difference, and the squared first-difference of the rates of price and wage inflation. As shown in the appendix, in the linearized model, the natural rate of output, $y_{t}^{n}$, is a function of leads and lags of the technology and preference shocks.

After many steps, the second-order approximation to period utility can be written as

$$
\frac{\Xi_{c, t}\left(C_{t}-\eta C_{t-1}\right)^{1-\sigma}\left(\bar{L}-L_{u, t}\right)^{\zeta(1-\sigma)}}{1-\sigma}=\text { T.I.P. }-\mathcal{L}=\text { T.I.P. }-\mathcal{L}_{x}-\mathcal{L}_{p}-\mathcal{L}_{w}
$$

where T.I.P refers to terms that are independent of monetary policy and

$$
\begin{gathered}
\mathcal{L}_{x}=\left(C_{*}-\eta C_{*}\right)^{1-\sigma}\left(\bar{L}-L_{u, *}\right)^{\zeta(1-\sigma)}\left\{\begin{array}{c}
\frac{1}{2} \cdot \frac{1-\zeta(1-\sigma)}{\zeta} \cdot\left(\frac{1-\beta \eta}{1-\eta}\right)^{2} x_{t}^{2} \\
+\frac{1}{2} \cdot \frac{\sigma}{(1-\eta)^{2}} \cdot\left(x_{t}-\eta x_{t-1}\right)^{2}
\end{array}\right. \\
\left.\quad+(1-\sigma) \cdot \frac{1-\beta \eta}{(1-\eta)^{2}} x_{t}\left(x_{t}-\eta x_{t-1}\right)\right\}, \\
\mathcal{L}_{p}=\left(C_{*}-\eta C_{*}\right)^{1-\sigma}\left(\bar{L}-L_{u, *}\right)^{\zeta(1-\sigma)}\left\{\frac{1}{2} \cdot \frac{1-\beta \eta}{1-\eta} \cdot \frac{\Theta_{p} \Pi_{p, *}}{\kappa_{p}} \cdot\left(\pi_{p, t}-\gamma_{p} \pi_{p, t-1}\right)^{2}\right\}, \text { and } \\
\mathcal{L}_{w}=\left(C_{*}-\eta C_{*}\right)^{1-\sigma}\left(\bar{L}-L_{u, *}\right)^{\zeta(1-\sigma)}\left\{\frac{1}{2} \cdot \frac{1-\beta \eta}{1-\eta} \cdot \frac{\Theta_{w} \Pi_{w, *}}{\kappa_{w}} \cdot\left(\pi_{w, t}-\gamma_{w} \pi_{w, t-1}\right)^{2}\right\} .
\end{gathered}
$$


In our welfare calculations, we ignore the T.I.P. terms and focus on the terms related to the output gap and price and wage inflation rates.

The three elements in $\mathcal{L}_{x}$ correspond to the period welfare costs associated with output deviating from its natural rate. Owing to habit formation, both the level of the output gap and its quasi-difference affect welfare. All three preference parameters enter the coefficients of the welfare loss for these terms. The terms in $\mathcal{L}_{p}$ and $\mathcal{L}_{w}$ correspond to the welfare loss associated with adjustment costs in changing prices and wages. The coefficients in these terms depend primarily on the parameters associated with nominal rigidities. The welfare costs of sticky prices and wages are inversely related to the price and wage sensitivity parameters, $\kappa_{p}$ and $\kappa_{w}$. The more flexible are prices, the smaller are the welfare costs implied by a given magnitude of inflation fluctuations, and similarly for wages.

Based on the parameter point estimates, the weights on wage and price inflation gaps are significantly greater than those on the output gap terms, reflecting the high estimated degree of stickiness in wage and price setting (i.e., low estimated values of $\kappa_{w}$ and $\kappa_{p}$ ). Table 2 reports the implied relative weights on the terms related to the output gap and the first-differences of wage and price inflation, where we have normalized the values of the weights by the weight on the price inflation term at the point estimate. The first row reports the sum of the weights on the three terms in the loss associated with the output gap and its quasi-difference. ${ }^{9}$ The first column reports the weights computed at the parameter point estimates. The second column reports the median values of the weights based on the estimated distribution of the parameter values, approximated using 1000 draws from the normal distribution with the estimated covariance for the parameter estimates, where we truncate the parameter values at the lower ends of their distributions as follows: $\sigma$ at $0.5, \zeta$ at 0.1 , and $\eta$ at 0 . The median values of the weights are close to those implied by the point estimates. At the point estimates, the variance in wage inflation gets a weight 1.7 times that of price inflation, due to the estimated value of $\kappa_{w}$ being about 60 percent as large as that for $\kappa_{p}$. The weights on the variances of the output gap and the quasi-difference of the output gap are somewhat smaller than that of inflation, but are somewhat higher than typically seen in the literature due to our relatively high estimate of $\sigma$.

The variation in the weights of the loss function implied by parameter uncertainty is

\footnotetext{
${ }^{9}$ At the point estimates, the weights on the squared level of the output gap and on the squared quasidifference term are about equal, while that on the cross-product is smaller with the opposite sign.
} 
Table 2: Relative Weights in Central Bank Loss

\begin{tabular}{lrrcr}
\hline \hline $\begin{array}{l}\text { Weight } \\
\text { in Loss }\end{array}$ & $\begin{array}{c}\text { Point } \\
\text { Estimate }\end{array}$ & $\begin{array}{c}\text { Median } \\
\text { Estimate }\end{array}$ & $\begin{array}{c}70 \text { Percent } \\
\text { Interval }\end{array}$ & $\begin{array}{c}\text { Mean } \\
\text { Estimate }\end{array}$ \\
\hline$\omega_{x}$ & 0.06 & 0.04 & {$[0.0,8.7]$} & 8.28 \\
$\omega_{p}$ & 1.00 & 0.92 & {$[0.0,159.1]$} & 132.45 \\
$\omega_{w}$ & 1.71 & 1.55 & {$[0.0,270.6]$} & 211.31 \\
\hline \hline
\end{tabular}

enormous, reflecting the nonlinear relationship between the parameter values and the loss weights. The third column reports the estimated 70 percent confidence of the weights. At the lower end of the 70 percent confidence interval, the weights are very close to zero. However, at the upper end, corresponding to high values of $\sigma$ and $\zeta$, the weights are about 150 times larger than those implied by the point estimates. The preference parameters have a large effect on steady-state utility, which affects all loss-function weights and makes them highly correlated. However, the ratio of the weights varies relatively little over the draws. For example, the standard deviation of the ratio of the sum of the output gap weights to the weight on price inflation gaps is 0.01 and the ratio of the weight on wage inflation gaps to that on price inflation gaps is about 0.1 . The mean values of the weights are dominated by the upper end of the distribution of weights, which are between two and three times larger than those based on the point estimates, reflecting the fact that the weights depend in part on the inverse of some parameter values.

\subsection{Optimal monetary policy with no parameter uncertainty}

In our analysis of optimal monetary policies, it is important to be clear what information the central bank has available in making its decision. We assume the central bank knows the structure of the model. At the time of making its policy decision, the central bank is assumed to observe all past observable data, but not the realization of the current shock. In the case of no parameter uncertainty, the central bank is able to infer the past values of the natural rates of interest, hours, and output from the observable data.

We first compute the optimal certainty equivalent policy based on the point estimates of the model parameters. The resulting policy and outcomes provide a useful benchmark for the policy rules that we examine. The optimal certainty equivalent policy maximizes 
the quadratic approximation of welfare, subject to the constraints implied by the linearized model. Throughout, in computing the welfare loss we assume a discount rate arbitrarily close to zero, so that we are maximizing the unconditional measure of welfare. We compute the fully optimal policy using Lagrangian methods as described in Finan and Tetlow (1999), adapted to take account of assumption of date $t-1$ information in the implementation of monetary policy. The standard deviations of the technology and preference shocks (the only stochastic elements in the model) are set to their corresponding estimated values of 0.64 and 6.17 percentage points, respectively. (See Appendix B for the calculation of these values.)

The results under the optimal policy are shown in the first column of Table 3 . The middle portion of the table shows the resulting welfare losses. The first row of this part of the table reports the overall welfare loss, $\mathcal{L}$. Because the units of the welfare loss are difficult to interpret, the next four rows of the table report the welfare losses (and its component parts) measured in terms "consumption-equivalent" units, denoted by $\mathcal{C}$, equal to the percentage point reduction in steady-state consumption (absent fluctuations) that would yield the same welfare loss as implied by fluctuations in the output gap and wage and price inflation rates around their steady state values. The lower part of the table reports the resulting unconditional standard deviations of the output gap, the first-differences of the price and wage inflation rates, and the level of the nominal interest rate.

The "consumption equivalent" welfare loss is extremely small under the optimal monetary policy with no uncertainty, about $1 / 200$ th of one percent of consumption. This tiny loss reflects the fact that the preference and technology shocks do not create significant tradeoffs between the objectives in the loss. Indeed, were it not for the assumption that policy acts using lagged information, the preference shock would generate no welfare loss under optimal policy through its contribution to fluctuations in the output gap and wage and price inflation while the technology shock would engender only very small welfare losses (reflecting the tradeoff implied by the presence of sticky wages). The technology shock does entail a tradeoff owing to the presence of sticky wages, but under the optimal policy, the resulting loss is very modest. Under the fully optimal monetary policy, variability in the output gap and the first differences in the rates of wage and price inflation are all reduced to nearly zero. In terms of the annualized rate, the standard deviations of both wage and price inflation are about 0.1 percentage point. The optimal policy induces considerable interest 
Table 3: Performance of Alternative Monetary Policies

\begin{tabular}{|c|c|c|c|c|c|c|c|c|}
\hline & \multicolumn{4}{|c|}{ No Uncertainty } & \multicolumn{4}{|c|}{ Parameter Uncertainty } \\
\hline & $\begin{array}{l}\text { Optimal } \\
\text { Policy }\end{array}$ & \multicolumn{3}{|c|}{$\begin{array}{l}\text { Policy Rule } \\
\text { Coefficients }\end{array}$} & $\begin{array}{l}\text { Optimal } \\
\text { Policy }\end{array}$ & \multicolumn{3}{|c|}{$\begin{array}{l}\text { Policy Rule } \\
\text { Coefficients }\end{array}$} \\
\hline$r^{n}$ & & & & .84 & & & & 1.00 \\
\hline$x$ & & 27.88 & & .12 & & 7.02 & & 1.46 \\
\hline$\pi_{p}$ & & .01 & 566.78 & 391.40 & & 15.39 & 617.80 & 480.86 \\
\hline \multirow[t]{2}{*}{$\pi_{w}$} & & & 1000.00 & 693.78 & & & 1000.00 & 780.89 \\
\hline & \multicolumn{8}{|c|}{ Welfare Losses } \\
\hline $\mathcal{L}$ & 717.8 & 771.1 & 742.5 & 719.2 & $1.98 \mathrm{E} 7$ & $5.20 \mathrm{e} 7$ & $2.20 \mathrm{E} 7$ & $1.99 \mathrm{E} 7$ \\
\hline $\mathcal{C}$ & .006 & .007 & .007 & .006 & .007 & .010 & .007 & .007 \\
\hline $\mathcal{C}_{x}$ & .001 & .002 & .001 & .001 & .001 & .004 & .002 & .002 \\
\hline $\mathcal{C}_{p}$ & .003 & .003 & .003 & .003 & .003 & .003 & .003 & .003 \\
\hline \multirow[t]{2}{*}{$\mathcal{C}_{w}$} & .002 & .002 & .002 & .002 & .002 & .002 & .002 & .002 \\
\hline & \multicolumn{8}{|c|}{ Standard Deviations } \\
\hline$x$ & .08 & .10 & .09 & .08 & .09 & .16 & .11 & .10 \\
\hline$\Delta \pi_{p}$ & .03 & .03 & .03 & .03 & .03 & .03 & .03 & .03 \\
\hline$\Delta \pi_{w}$ & .02 & .02 & .02 & .02 & .02 & .02 & .02 & .02 \\
\hline$r$ & 2.59 & 2.69 & 2.38 & 2.59 & 2.59 & 2.22 & 2.51 & 2.94 \\
\hline
\end{tabular}

rate variability in response to these two shocks, with the standard deviation of the nominal (annualized) interest rate of over 10 percentage points. This variability implies that the zero lower bound on nominal interest rate is a relevant concern, but we leave incorporating this constraint to future research.

\subsection{Alternative monetary policy rules}

In the presence of parameter uncertainty, it is useful to analyze monetary policy in terms of a policy rule in which the policy instrument depends on a small number of variables. For this purpose, we consider three parsimonious monetary policy rules, each of which yields a welfare loss that is very close to the fully optimal policy when all parameters are known.

The general specification is a Taylor-type policy rule where the nominal interest rate is determined by the lagged values of the central bank estimate of the natural rate of interest, 
$\hat{r}_{t}^{n}$, the central bank estimate of the output gap, $\hat{x}_{t}$, and the rates of price and wage inflation:

$$
r_{t}=\pi_{p, t-1}+\phi_{r^{n}} \hat{r}_{t-1}^{n}+\phi_{x} \hat{x}_{t-1}+\phi_{p} \pi_{p, t-1}+\phi_{w} \pi_{w, t-1} \text {. }
$$

With known parameters, the central bank estimates of the natural rates are assumed to equal their respective true values; with parameter uncertainty, these estimates suffer from measurement error, as discussed in the next section. Note that we have assumed that policy responds to the lagged values of these variables, in keeping with our assumption that policy is set using $t-1$ information. ${ }^{10}$ Throughout the following, we restrict the policy rule coefficient on price inflation to be no smaller than 0.01 and we do not allow any coefficients to exceed $1000 .^{11}$

We consider three types of policy rules. The first is a version of the standard Taylor Rule, where the interest rate is determined by inflation and the output gap. The second is a rules that responds only to wage and price inflation. The third is a generalization of the other rules that is exactly as specified in equation (10). This rule is used as a close approximation for the fully optimal rule, but has the advantage that the coefficients are easier to interpret. We compute the optimal coefficients of each rule to maximize unconditional welfare of the representative household using a numerical hill-climber routine, as described in Levin, Wieland, and Williams (1999). Absent parameter uncertainty, the optimized versions of all three rules yield welfare losses close to that which obtains under the fully optimal policy.

The optimized Taylor rule (the second column of Table 3) acts like a strict output targeting policy that aims to keep the output gap near zero at all times. This rule has the minimum allowable coefficient on price inflation and a very large coefficient on the output gap. The policy rule that responds to wage and price inflation (the third column of Table 3) behaves like a targeting rule that aims to maintain a negative correlation between the rates of price and wage inflation, with the latter more tightly controlled. The optimized coefficients exhibit massive responses to wage and price inflation, with the coefficient on wage inflation about 1.76 times as large as that for price inflation. This is nearly identical to the ratio of 1.71 of the weights in the objective function of wage to price inflation. The optimized generalized policy rule (the fourth column of Table 3) is characterized by a significant response to the natural rate of interest, a modest response to the output gap,

\footnotetext{
${ }^{10}$ Another approach would be to specify the rule in terms of $t-1$ expectations of current-period variables.

${ }^{11}$ In the case where this upper bound is a binding constraint, the loss surface is nearly flat in the vicinity of the reported parameter values and increasing the upper bound has only a trivial effect on welfare.
} 
and very large responses to the rates of price and wage inflation. This rule behaves much like the rule that targets a combination of wage and price inflation; the ratio of coefficients on wage and price inflation are nearly the same in the two cases. This generalized rule yields a welfare loss that is nearly identical to that under the fully optimal policy.

\section{Monetary Policy under Parameter Uncertainty}

In this section, we analyze the performance and robustness of monetary policies under parameter uncertainty where the central bank maximizes expected welfare. The only form of uncertainty that the policymaker is assumed to face is uncertainty regarding model parameters owing to sample variation. In particular, we assume that the central bank knows the true model and that the model is estimated using a consistent estimator and that the central bank is certain that the model and the estimation methodology are correct. ${ }^{12}$ We abstract from learning and assume that the policymaker's knowledge and uncertainty do not change over time. We assume that private agents know everything, including the central bank's parameter estimates. For a given specification of monetary policy, expected welfare is approximated by numerically integrating the welfare outcomes over a sample drawn from the distribution of the five estimated structural parameters implied by the estimated covariance matrix.

\subsection{Natural rate uncertainty}

Before proceeding with the analysis of monetary policy rules, we first provide some summary measures of the degree of uncertainty regarding the natural rates of hours, output, and interest owing to parameter uncertainty. In this model, the responses of the natural rates to technology and preference shocks depend on three parameters describing household preferences: $\sigma, \eta$, and $\zeta$. Throughout the remainder of the paper, we assume that the distribution of model parameters is jointly normal distributed with mean zero and covariance

\footnotetext{
${ }^{12}$ The assumption that the policymaker is certain about the correctness of the estimation methodology likely reduces the degree of parameter uncertainty relative to what policymakers face in reality. For example, in the model used in this paper, some parameter point estimates can vary significantly, depending on sample and specifics of the estimation method. We leave the study of this broader form of estimation uncertainty to future work.
} 
given by the estimated covariance matrix. We approximate this distribution with a single set of 1000 draws from the estimated covariance matrix, truncated as described in section 3 .

In general, parameter uncertainty implies uncertainty both about the steady-state values of natural rates as well as their movements over time. However, in the stylized model that we study here, the steady-state natural rate of interest depends only on the household's discount rate, which is assumed to be known by the policymaker. Therefore, uncertainty about the natural rate of interest is limited to its deviations from steady-state. The steadystate level of hours (and thereby output) depends on estimated structural parameters and the value of the time endowment. Our estimation methodology does not use information on levels of variables, so we do not have an empirical measure of uncertainty regarding the steady-state level of hours. For simplicity, we assume that the policymaker, by observing a long time series on hours, is able to estimate the mean level of hours precisely. We assume that the policymaker has no independent knowledge of the time endowment, so perfect knowledge of the mean level of hours has no implications for uncertainty about other preference parameters. We note that under less restrictive assumptions, there exist tight links between estimated structural parameters and steady-state values, which affect both model estimation and the analysis of parameter uncertainty. Indeed, Laubach and Williams (2003) find evidence of considerable uncertainty regarding low-frequency components of natural rates of interest and output, suggesting that the assumption that the steady-state levels are known with certainty is untenable in practice. We leave consideration of uncertainty about steady-state values in a micro-founded model to future research.

The responses of natural rates to technology and preference shocks depend on the parameter values describing preferences. The thick solid line in the upper panel of Figure 4 plots the impulse response of the log of the natural rate of hours to one standard deviation positive innovations to technology and preferences, implied by the point estimates of the model parameters. (Note that the log of the natural rate of hours equals the log of the natural rate of output minus the log of TFP.) The thin solid lines show the median responses of the natural rate of hours, calculated from impulse responses from 1000 draws from the estimated parameter distribution. The dashed and dashed-dotted lines show the boundaries of the 70 and 95 percent confidence bands of the impulse responses, respectively. The lower panel of the figure shows the corresponding outcomes for the natural rate of interest (measured at an annualized rate). Note that the model implies that there is no uncertainty 
about the long-run effects of technology or preference shocks on the natural rates of hours and interest, as both of which eventually return to their respective steady-state values.

We assume that the central bank computes its estimates of natural rates based on the point estimates of the preference parameters. ${ }^{13}$ We measure natural rate misperceptions as the difference between the level of the natural rate implied by the actual parameter values and the level implied by the point estimates of the model parameters. Averaging over the 1000 draws from the parameter distribution, the root mean squared deviation of the true natural rate of output and the central bank's estimate (computed using the parameter point estimates) is a rather modest 0.13 percentage point. The mean first-order autocorrelation of this difference is 0.84 . The root mean squared deviation of the true natural rate of interest from the central bank's estimate is a more sizable 1.05 percentage points (measured at an annual rate), with a mean first-order autocorrelation of 0.35 .

\subsection{Optimal monetary policy under parameter uncertainty}

In order to provide a benchmark for policies under uncertainty, we first compute the optimal outcome if the policymaker knew all the parameter values and followed the fully optimal policy in each case. The results in the fifth column of Table 3. Of course, given that the parameters are uncertain, this outcome is not obtainable in practice, but this exercise provides a benchmark against which we can measure the welfare costs associated with parameter uncertainty. As can be seen from comparing the first and fifth columns of the table, the mean welfare loss under the first-best optimal policy is considerably larger than that computed at the parameter point estimates. This reflects the fact that the mean weights in the welfare loss are higher than the weights evaluated at the point estimates. That said, the consumption-equivalent welfare losses and the the variability of key variables is about the same on average as under the optimal policy evaluated at the parameter point estimates.

We now examine the characteristics and performance of the implementable monetary policy rules introduced in the previous section. We first consider the performance of the rules that were found to be optimal absent parameter uncertainty, then we reoptimize the coefficients of these policy rules to minimize the expected welfare loss under parameter

\footnotetext{
${ }^{13}$ The central bank could use other methods to estimate the natural rates that take into account parameter uncertainty, but our approach seems a reasonable benchmark for our analysis.
} 
uncertainty. As noted above, in implementing these rules, we assume the central bank computes its estimates of natural rates using the point estimates of the parameters. For each draw from the parameter distribution, the realizations of the natural rates (and all other variables) are generated by the model based on the parameter values drawn.

The optimized Taylor rule assuming no parameter uncertainty does not yield a unique stable rational expectations equilibrium for 17 of the 1000 draws of parameter values drawn from the posterior distribution. The source of the problem is that the response to the output gap is excessively large and this creates instability in the system. The other two policies yield a unique solution for all 1000 draws and deliver mean outcomes that are close to what obtains if the coefficients of the rules are reoptimized under parameter uncertainty.

Relative to the case of no parameter uncertainty, the optimized standard Taylor rule under parameter uncertainty responds far less aggressively to the estimate of the output gap (a coefficient of 7 compared to nearly 28) and more strongly to inflation (a coefficient of over 15 compared to .01). This rule yields a unique solution in all 1000 draws from the parameter distribution. The results for this rule are shown in the sixth column of the table. This dramatic change in the characteristics of the optimal Taylor rule is due to the mismeasurement of the natural rate of output under parameter uncertainty. In fact, if the central bank faced parameter uncertainty but somehow knew the true values of the natural rate of output, the optimized Taylor rule would be characterized by a very small response to inflation and a very large response to the output gap. However, in the presence of natural rate uncertainty, a very large response to the output gap generates correspondingly large policy errors. In order to minimize this source of undesired fluctuations and to offset the effects of the resulting policy errors on inflation, the optimized Taylor rule under parameter uncertainty responds much more modestly to the perceived output gap and much more strongly to inflation.

Optimized policy rules that respond to wage and price inflation, but not output, are very effective at minimizing the mean welfare loss under parameter uncertainty. The results for this rule are shown in the seventh column of the table. The optimized rule yields a welfare loss close to the first-best allocation, and performs better than the optimized Taylor rule. The coefficients display the same characteristics as in the case of no parameter uncertainty: the coefficient on wage inflation is at its maximum value of 1000 , and the ratio of the wage inflation coefficient to the price inflation coefficient is about 1.6, slightly smaller than in the 
case of no uncertainty. Evidently, responding to aggressively to the wage and price inflation rates substitutes for responding to the output gap in this model.

Finally, the generalized rule yields expected welfare nearly the same as the theoretical first-best. Thus, from a Bayesian perspective, knowledge of the exact draw of parameter values has little benefit in terms of expected welfare. This rule responds fully to the natural rate of interest (we imposed an upper bound on this coefficient of one), moderately to the output gap, and massively to the rates of wage and price inflation. The results are reported in the final column of the table. Although the response to the output gap is larger than in the case of no parameter uncertainty, the behavior of policy is dominated by the responses to wage and price inflation that are two orders of magnitude larger than the response to the output gap. Interestingly, this rule responds more aggressively to the observable variables than its counterpart derived assuming no parameter uncertainty. Thus, in this microfounded DSGE model, parameter uncertainty leads to a more aggressive monetary policy rule, rather than a less responsive one, as in Brainard's (1967) analysis using a traditional model.

\section{Calvo Wage and Price Contracts}

We now examine the characteristics of optimal monetary policies assuming Calvo-style contracts that are commonly assumed in the literature, rather than quadratic adjustment costs. Under suitable assumptions, the Calvo contract model yields the same log-linear first-order dynamics, but a different second-order approximation to welfare. Unlike the quadratic

adjustment cost model, the assumption of Calvo contracts implies heterogeneity across agents in wages and prices. Most significantly, this implies differences in labor supply and consumption across households, which, given our assumption of nonseparable preferences over consumption and leisure, greatly complicates aggregation of the model. Additional assumptions, however, such as those made by Smets and Wouters (2003), makes aggregation of first-order dynamics and welfare more tractable. Specifically, we assume that each household contains a continuum of members that replicate the distribution of types of labor in the economy and each household shares its resources across its members optimally. In this way, we are able to derive tractable analytical expressions for the first-order aggregate dynamics and the second-order approximation to welfare. 
Table 4: Performance of Monetary Policies: Calvo Contracts

\begin{tabular}{|c|c|c|c|c|c|c|c|c|}
\hline & \multicolumn{4}{|c|}{ No Uncertainty } & \multicolumn{4}{|c|}{ Parameter Uncertainty } \\
\hline & $\begin{array}{c}\text { Optimal } \\
\text { Policy }\end{array}$ & \multicolumn{3}{|c|}{$\begin{array}{l}\text { Policy Rule } \\
\text { Coefficients }\end{array}$} & $\begin{array}{c}\text { Optimal } \\
\text { Policy }\end{array}$ & \multicolumn{3}{|c|}{$\begin{array}{l}\text { Policy Rule } \\
\text { Coefficients }\end{array}$} \\
\hline$r^{n}$ & & & & .78 & & & & 1.00 \\
\hline$x$ & & 26.84 & & 8.68 & & 16.16 & & 5.57 \\
\hline$\pi_{p}$ & & .01 & 138.25 & 15.64 & & .05 & 178.58 & 23.14 \\
\hline \multirow[t]{2}{*}{$\pi_{w}$} & & & 1000.00 & 324.46 & & & 1000.00 & 256.18 \\
\hline & \multicolumn{8}{|c|}{ Welfare Losses } \\
\hline $\mathcal{C}$ & .034 & .102 & .036 & .034 & .035 & .105 & .037 & .035 \\
\hline $\mathcal{C}_{x}$ & .019 & .002 & .021 & .019 & .020 & .004 & .018 & .018 \\
\hline $\mathcal{C}_{p}$ & .005 & .003 & .005 & .005 & .005 & .003 & .005 & .005 \\
\hline \multirow[t]{2}{*}{$\mathcal{C}_{w}$} & .010 & .097 & .010 & .010 & .010 & .098 & .014 & .013 \\
\hline & \multicolumn{8}{|c|}{ Standard Deviations } \\
\hline$x$ & .43 & .10 & .45 & .44 & .44 & .15 & .34 & .34 \\
\hline$\Delta \pi_{p}$ & .04 & .03 & .04 & .04 & .04 & .03 & .04 & .04 \\
\hline$\Delta \pi_{w}$ & .01 & .02 & .01 & .01 & .01 & .02 & .01 & .01 \\
\hline$r$ & 2.53 & 2.62 & 2.36 & 2.53 & 2.63 & 2.27 & 2.48 & 2.61 \\
\hline
\end{tabular}

The relationship between the coefficient on the driving process in the equation describing the first-order of product prices, $\kappa_{p}$, and the coefficient on the variability of price inflation in the second-order approximation to household welfare is identical for the quadratic adjustment costs model and the Calvo contract model. For wages, however, the relationship differs for the two models. In particular, under Calvo-style wage setting, an additional term, equal to $\left(1+\theta_{w}\left(\frac{1-\zeta(1-\sigma)}{\zeta}\right)\left(\frac{1-\beta \eta}{1-\eta}\right)\right)$ multiplies the coefficient on wage inflation variability in the loss function. Given the estimated and calibrated parameter values, this additional term is relatively large and implies notably greater weight on wage inflation than in the model with quadratic adjustment costs.

Qualitatively, the results regarding the effects of uncertainty on optimal policy are the same with Calvo contracts as with quadratic adjustment costs. Table 4 reports the results of our policy experiments using Calvo wage and price contracts. In the case of the Taylor rule, the optimal coefficient on the output gap is smaller and the coefficient on price inflation is larger with parameter uncertainty than absent parameter uncertainty, just as with quadratic 
adjustment costs. And, as before, the rule that responds solely to wage and price inflation come very close to matching the first-best outcome, while the standard Taylor rule performs less well. The relative response to wage inflation compared to price inflation is significantly greater than before, owing to the greater welfare costs to fluctuations in wages under Calvo contracts.

\section{Conclusion}

This paper has examined the implications of parameter uncertainty for the design of optimal monetary policy in an estimated micro-founded macroeconomic model. In micro-founded models of this type, parameter uncertainty implies joint uncertainty about model dynamics, natural rates, and the welfare costs of fluctuations. We find that optimal Taylor rules respond less to output and more to inflation in the presence of parameter uncertainty. We also show that policy rules that focus solely on stabilizing wages and prices, rather than output, perform better than Taylor rules. Our analysis can be extended to model that include additional features of the economic landscape and associated uncertainty, including a richer description of the economy, a wider set of sources of aggregate fluctuations, and uncertainty regarding the structure of the economy. One potentially important direction for future research is the incorporation of imperfect information on the part of private agents as well. 


\section{References}

[1] Altig, David, Lawrence J. Christiano, Martin Eichenbaum, and Jesper Linde. "Technology Shocks and Aggregate Fluctuations." Federal Reserve Bank of Chicago, manuscript, June 2002.

[2] Amato, Jeffery, and Thomas Laubach. "Estimation and Control of an OptimizationBased Model with Sticky Prices and Wages." Journal of Economic Dynamics and Control 27 (7), May 2003, 1181-1215.

[3] Aoki, Kosuke, and Kalin Nikolov. "Rule-based Monetary Policy under Central Bank Learning." Bank of England, mimeo, March 2004.

[4] Brainard, William C. "Uncertainty and the Effectiveness of Policy." American Economic Review 57, 1967, 411-425.

[5] Calvo, G. "Staggered Prices in a Utility-Maximizing Framework." Journal of Monetary Economics, 12 (3), September 1983, 383-398.

[6] Canova, Fabio, and Luca Sala. "Back to Square One: Identification Issues in DSGE Models.” European Central Bank, Working Paper 583, January 2006.

[7] Christiano, Lawrence J., Martin Eichenbaum, and Charles L. Evans. "Nominal Rigidities and the Dynamic Effects of a Shock to Monetary Policy." Journal of Political Economy 113 (1), February 2005, 1-45.

[8] Christiano, Lawrence J., Martin Eichenbaum, and Robert Vigfusson. "Assessing Structural VARs." NBER Macroeconomics Annual 21, 2006, 1-72.

[9] Clarida, Richard, Jordi Galí, and Mark Gertler. "Monetary Policy Rules and Macroeconomic Stability: Evidence and Some Theory." Quarterly Journal of Economics 115 (1), February 2000, 147-180.

[10] Erceg, Christopher J., Dale W. Henderson, and Andrew T. Levin. "Optimal Monetary Policy with Staggered Wage and Price Contracts." Journal of Monetary Economics, 46 (2), October 2000, 281-313. 
[11] Finan, Frederico, and Robert Tetlow. "Optimal Control of Large, Forward-Looking Models: Efficient Solutions and Two Examples." Federal Reserve Board, FEDS paper 1999-51, October 1999.

[12] Francis, Neville, and Valerie A. Ramey. "Is the Technology-Driven Real Business Cycle Hypothesis Dead? Shocks and Aggregate Fluctuations Revisited." Journal of Monetary Economics 52 (8), November 2005, 1379-1399.

[13] Galí, Jordi. "Technology, Employment, and the Business Cycle: Do Technology Shocks Explain Aggregate Fluctuations?" American Economic Review 89 (1), March 1999, 249-271.

[14] Giannoni, Marc. "Does Model Uncertainty Justify Caution? Robust Optimal Monetary Policy in a Forward-Looking Model." Macroeconomic Dynamics 6 (1), February 2002, 111-144.

[15] Hall, Alastair, Atsushi Inoue, James M. Nason, and Barbara Rossi. "Information criteria for Impulse Response Function Matching Estimation of DSGE Models." Federal Reserve Bank of Atlanta working paper 2007-10, May 2007.

[16] Iskrev, Nikolay. "How Much Do We Learn from the Estimation of DSGE Models? A Case Study of Identification Issues in a New Keynesian Business Cycle Model." Manuscript, University of Michigan, November 2007.

[17] Justiniano, Alejandro, and Bruce Preston. "Monetary Policy and Uncertainty in Empirical Small Open Economy Model." mimeo, 2008.

[18] Kehoe, Patrick J. "How to Advance Theory with Structural VARs: Use the SimsCogley-Nason Approach.” NBER Working Paper No. 12575, October 2006.

[19] Laubach, Thomas, and John C. Williams. "Measuring the Natural Rate of Interest," Review of Economics and Statistics 85 (4), 2003, 1063-1070.

[20] Laubach, Thomas, and John C. Williams. "The Response of Hours to Technology Shocks: Much Ado About Nothing?" Manuscript, Federal Reserve Bank of San Francisco, November 2006. 
[21] Levin, Andrew, Alexei Onatski, John Williams, and Noah Williams. "Monetary Policy Under Uncertainty in Micro-Founded Macroeconometric Models." NBER Macroeconomics Annual 2005, 229-289.

[22] Levin, Andrew, Volker Wieland, and John Williams. "Robustness of Simple Monetary Policy Rules under Model Uncertainty." In John Taylor (ed.), Monetary Policy Rules, Chicago, IL: The University of Chicago Press, 1999, 263-299.

[23] Levin, Andrew, and John C. Williams. "Parameter Uncertainty and the Central Bank's Objective Function." Manuscript, Federal Reserve Bank of San Francisco, October 2005.

[24] Lubik, Thomas, and Frank Schorfheide. "A Bayesian Look at New Open Economy Macroeconomics." NBER Macroeconomics Annual 2005, 313-366.

[25] Orphanides, Athanasios, and John C. Williams. "Robust Monetary Policy Rules with Unknown Natural Rates." Brookings Papers on Economic Activity 2002 (2), 63-118.

[26] Rotemberg, Julio J. "Sticky Prices in the United States." Journal of Political Economy, 90 (6), December 1982, 1187-1211.

[27] Rotemberg, Julio J. and Michael Woodford. "An Optimization-Based Econometric Framework for the Evaluation of Monetary Policy." NBER Macroeconomics Annual 1997, 297-346.

[28] Rudebusch, Glenn D. "Is the Fed Too Timid? Monetary Policy in an Uncertain World." Review of Economics and Statistics 83 (2), May 2001, 203-17.

[29] Shapiro, Matthew, and Mark Watson. "Sources of Business Cycle Fluctuations." NBER Macroeconomics Annual 1988, 111-148.

[30] Smets, Frank, and Raf Wouters. "An Estimated Stochastic Dynamic General Equilibrium Model of the Euro Area." Journal of the European Economic Association 1 (5), September 2003, 1123-1175.

[31] Taylor, John B. "Discretion versus Policy Rules in Practice." Carnegie-Rochester Conference Series on Public Policy 39, December 1993, 195-214. 
Figure 1: VAR and Model Responses to a Technology Shock
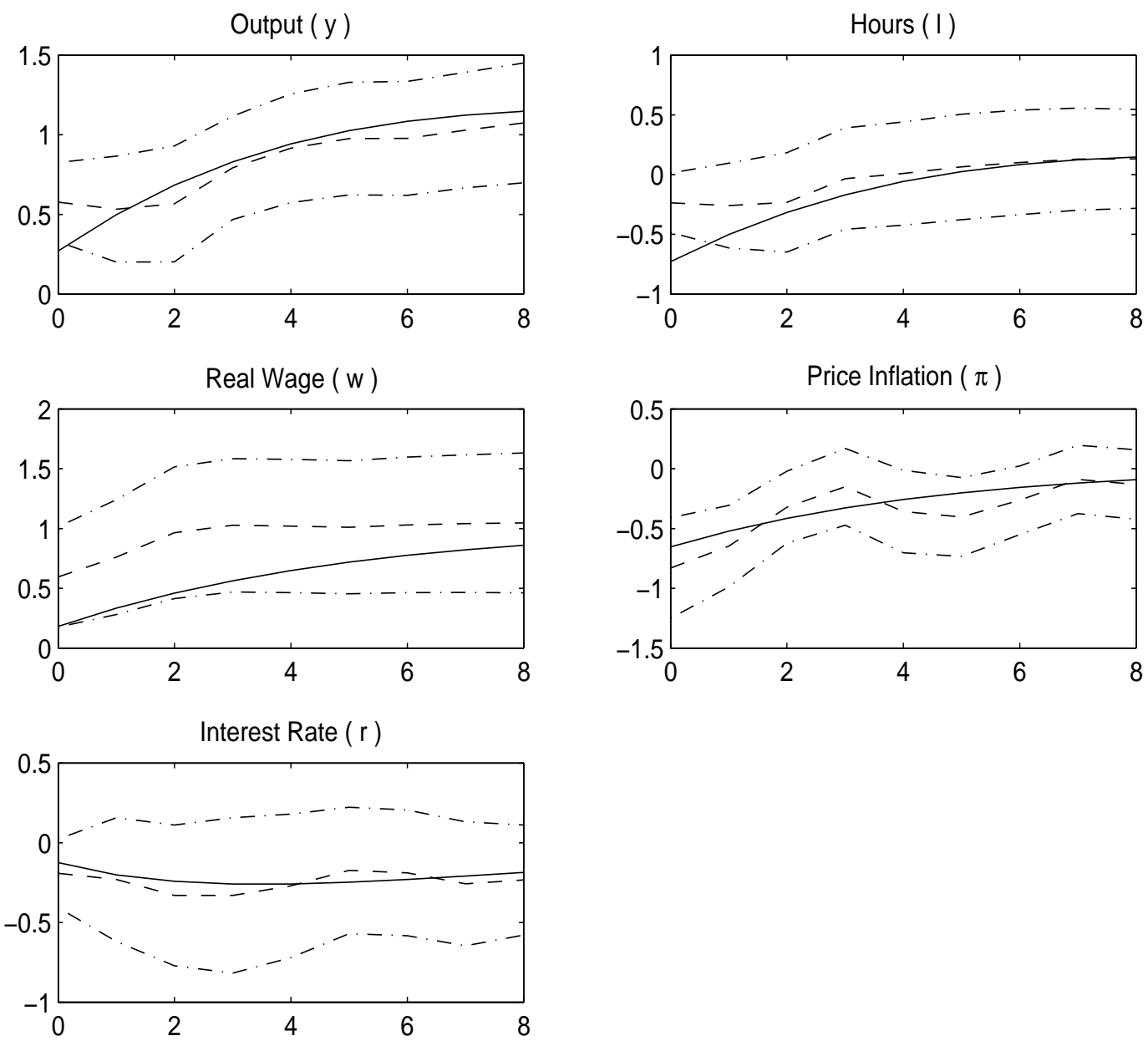

Notes: The dashed lines show the impulse responses implied by the VAR following an identified technology shock that raises output per hour permanently by 1 percent. The solid lines show the impulse responses implied by the model to a permanent shock to technology that has the same long-run effect on productivity as the technology shock in the VAR. The dashed-dotted lines are one standard error confidence intervals around the VAR responses. 
Figure 2: VAR and Model Responses to a Funds Rate Shock
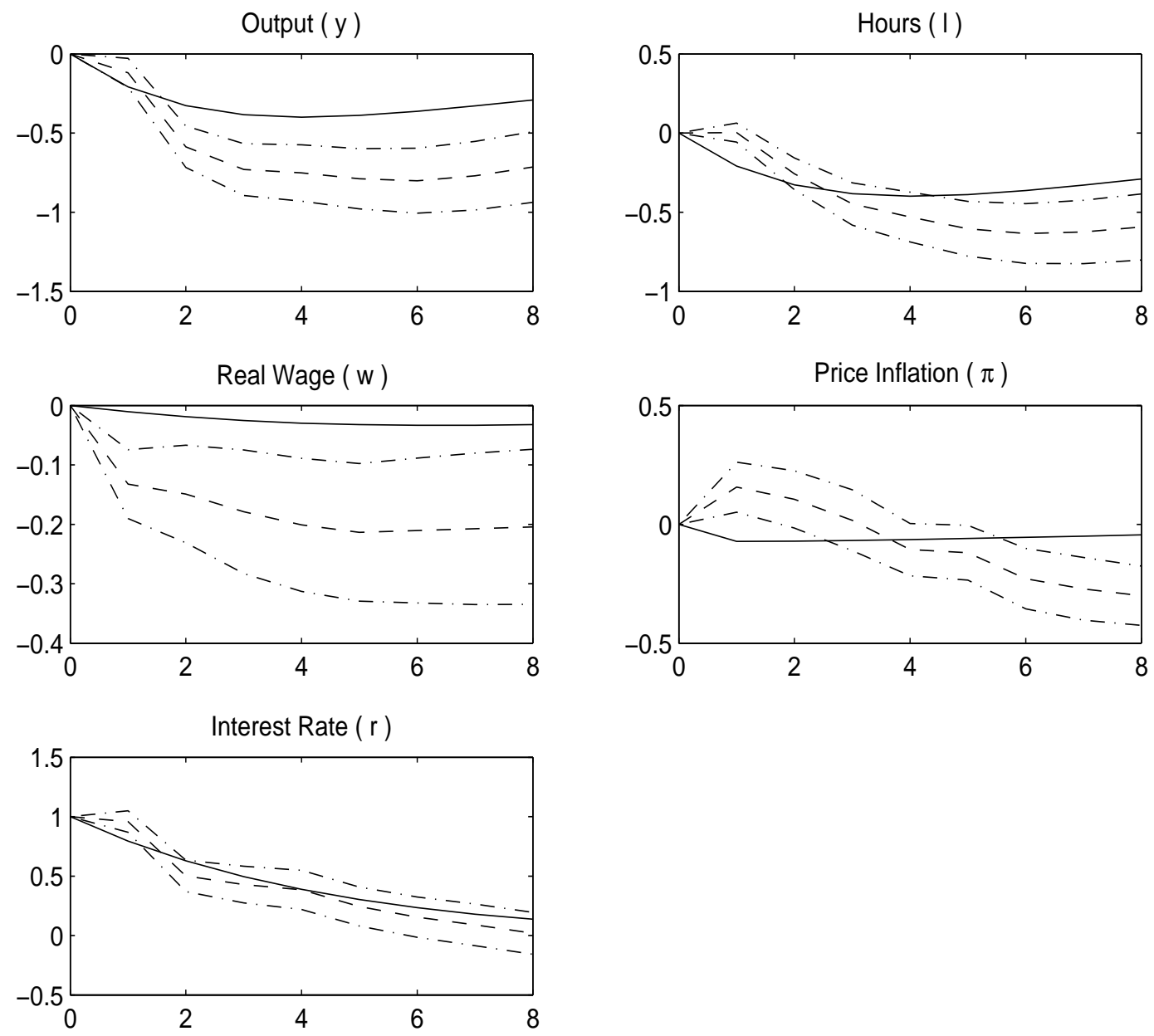

Notes: The dashed lines show the impulse responses implied by the VAR following a one percent funds rate shock. The solid lines show the impulse responses implied by the model to the same shock under the assumption that the contemporaneous response of all variables other than the funds rate is zero. The dashed-dotted lines are one standard error confidence intervals around the VAR responses. 
Figure 3: Identification of Key Model Parameters
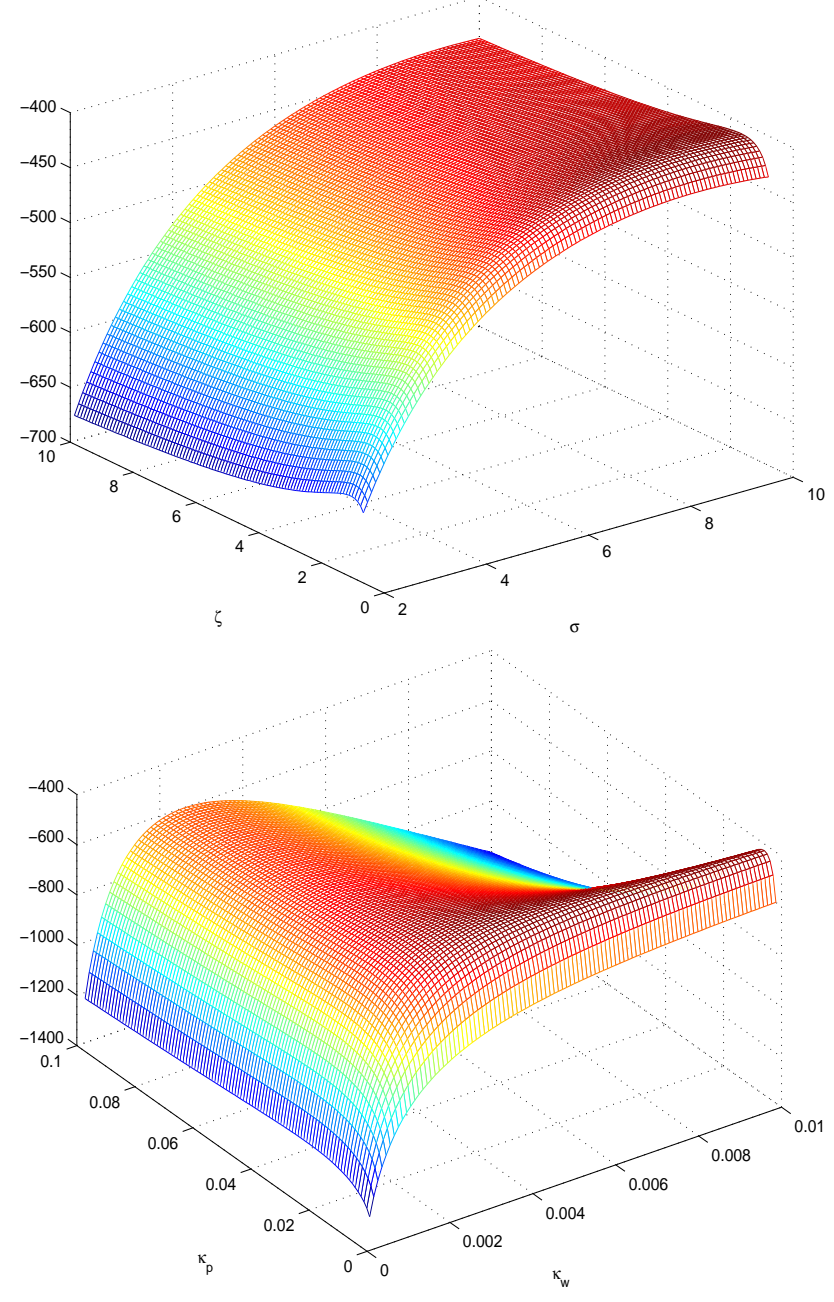

Notes: The upper panel of the figure shows the negative of the minimand in the parameter estimation as a function of combinations of $\sigma$ and $\zeta$, keeping all other parameters at their estimated values. The lower panel shows the negative of the minimand in the parameter estimation as a function of combinations of $\kappa_{w}$ and $\kappa_{p}$, keeping all other parameters at their estimated values. 
Figure 4: Natural Rate Uncertainty
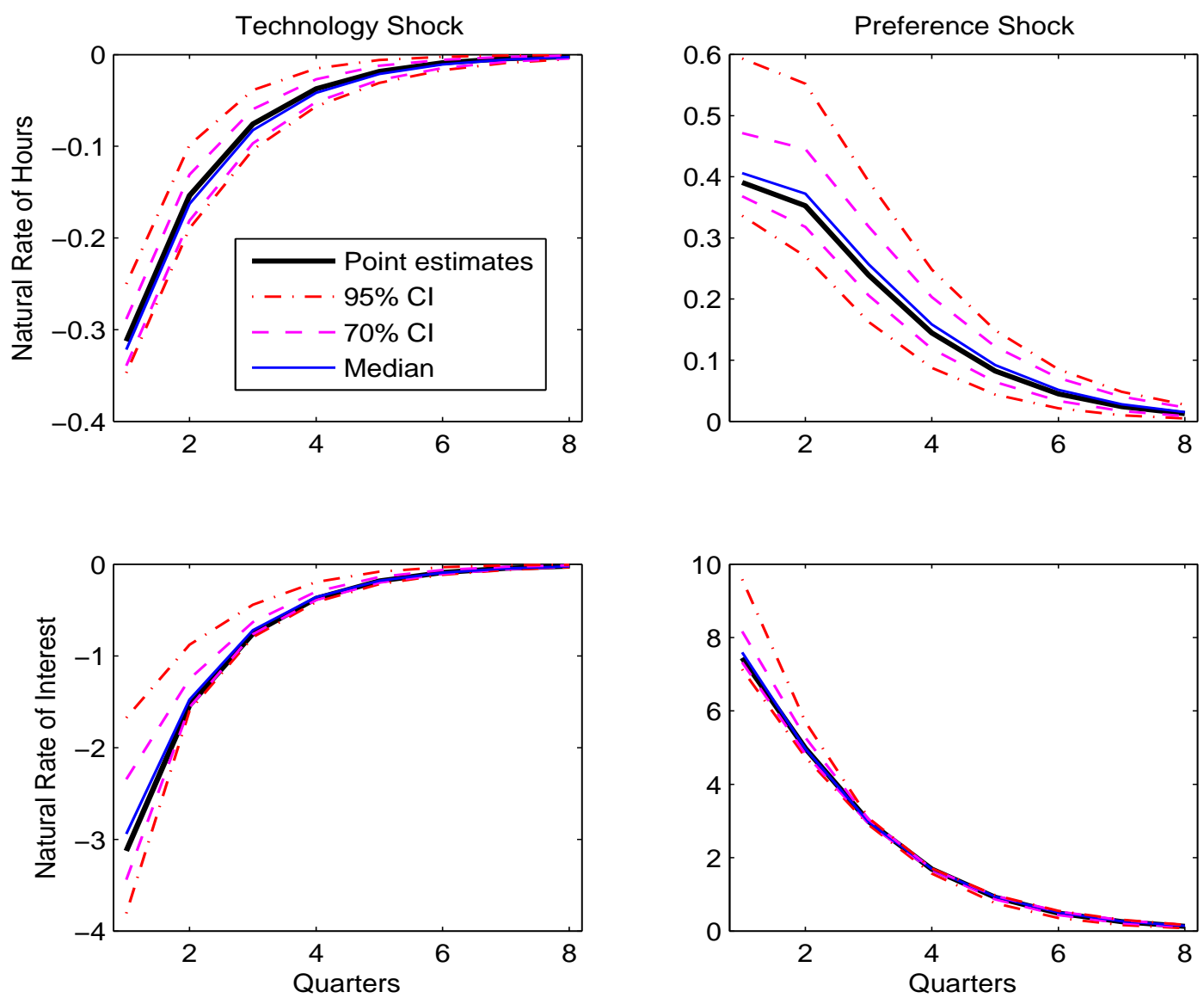

Notes: The thick solid lines show the model impulse responses of the natural rates to a one standard deviation point positive innovations to technology (left column) or preferences (right column), based on the parameter point estimates. The thin solid lines show the corresponding median responses computed from the distribution of the parameter estimates. The dashed and dashed-dotted lines indicate the corresponding 70 percent and 95 percent confidence intervals, respectively. 


\section{A The Linearized Model}

The first sub-section of this appendix gives the mathematical descriptions of the firms' and households' optimization problems, the second subsection reports the model's nonlinear equations, and the third sub-section reports the model's log-linear equations. We limit ourselves throughout in reporting just the equations from the symmetric model. The fourth sub-section reports the model's natural rates of output and interest.

\section{A.1 The firms' and households' optimization problems}

The final goods producing firm in each sector, taking as given the prices set by each intermediate-goods producer for their differentiated output, $\left\{P_{t}(j)\right\}_{j=0}^{1}$, solves

$$
\min _{\left\{Y_{f, t}(j)\right\}_{j=0}^{1}} \int_{0}^{1} P_{t}(x) Y_{f, t}(x) d x \text { s.t. } Y_{f, t} \leq\left(\int_{0}^{1} Y_{f, t}(x)^{\frac{\Theta_{p, t}-1}{\Theta_{p, t}}} d x\right)^{\frac{\Theta_{p, t}}{\Theta_{p, t}-1}} .
$$

This problem implies a demand function for each of the economy's intermediate goods given by $Y_{f, t}(j)=\left(P_{t}(j) / P_{t}\right)^{-\Theta_{p, t}} Y_{f, t}$, where the variable $P_{t}$ is the aggregate price level, defined by $P_{t}=\left(\int_{0}^{1}\left(P_{t}(x)\right)^{1-\Theta_{p, t}} d x\right)^{\frac{1}{1-\Theta_{p, t}}}$.

In the cost-minimization part of its problem, each intermediate-goods producing firm $j$, taking as given the wages $\left\{W_{t}(i)\right\}_{i=0}^{1}$ set by each household for its variety of labor, solves:

$$
\min _{\left\{L_{y, t}(i, j)\right\}_{i=0}^{1}} \int_{0}^{1} W_{t}(x) L_{y, t}(x, j) d x \text { s.t. } Y_{m, t}(j) \leq A_{t}\left(\int_{0}^{1} L_{y, t}(x, j)^{\frac{\Theta_{w, t}-1}{\Theta_{w, t}}} d x\right)^{\frac{\Theta_{w, t}}{\Theta_{w, t}-1}}
$$

This cost-minimization problem implies that the economy-wide demand for type $i$ labor is $L_{y, t}(i)=\int_{0}^{1} L_{y, t}(i, x) d x=\left(W_{t}(i) / W_{t}\right)^{-\Theta_{w, t}}\left(1 / A_{t}\right) \int_{0}^{1} Y_{m, t}(x) d x$ where $W_{t}$ denotes the aggregate wage, defined by $W_{t}=\left(\int_{0}^{1}\left(W_{t}(x)\right)^{1-\Theta_{w, t}} d x\right)^{\frac{1}{1-\Theta_{w, t}}}$. The marginal cost function of producing the intermediate goods is $M C_{t}(j)=W_{t} / A_{t}$.

In the profit-maximization part of the its problem, each intermediate-goods producing firm, taking as given the marginal cost $M C_{t}(j)$ for producing $Y_{m, t}(j)$, the aggregate price level $P_{t}$, and aggregate final-goods demand $Y_{f, t}$, solves,

$$
\max _{\left\{P_{t}(j)\right\}_{t=0}^{\infty}} E_{0} \sum_{t=0}^{\infty} \beta^{t} \frac{\Lambda_{c, t}}{P_{t}}\left\{\left(1+\varsigma_{\theta, p}\right) P_{t}(j) Y_{f, t}(j)-M C_{t}(j) Y_{m, t}(j)\right\}
$$

subject to

$$
Y_{f, t}(j)=Y_{m, t}(j)-\frac{\chi_{p}}{2}\left(\frac{P_{t}(j)}{P_{t-1}(j)}-\left(1-\gamma_{p}\right) \Pi_{p, *}-\gamma_{p} \Pi_{p, t-1}\right)^{2} Y_{m, t} \text { and } Y_{f, t}(j)=\left(\frac{P_{t}(j)}{P_{t}}\right)^{-\Theta_{p, t}} Y_{f, t},
$$


In (13) the discount factor that is relevant for discounting nominal revenues and costs between periods $t$ and $t+j$ is $E_{t} \beta^{j} \frac{\Lambda_{c, t+j} / P_{t+j}}{\Lambda_{c, t} / P_{t}}$, where $\Lambda_{c, t}$ is the household's marginal utility of consumption in period $t$. The parameter $\varsigma_{\theta, p}$ is the subsidy that we assume equals $\left.\left(\Theta_{p, *}-1\right)^{-1}\right)$, which ensures that in the absence of nominal rigidities the model's equilibrium outcome is Pareto optimal.

The household taking as given the expected path of the gross nominal interest rate $R_{t}$, the price level $P_{t}$, the aggregate wage rate $W_{t}$, its profits income, and its initial bond stock $B_{i, 0}$, solves:

$\max _{\left\{C_{t}(i), W_{t}(i)\right\}_{t=0}^{\infty}} E_{0} \frac{1}{1-\sigma} \sum_{t=0}^{\infty} \beta^{t} \Xi_{c, t}\left[\left(C_{t}(i)-\eta C_{t-1}(i)\right)\left(\bar{L}-L_{u, t}(i)\right)^{\zeta}\right]^{1-\sigma}$

subject to

$E_{t}\left[\beta \frac{\Lambda_{c, t+1} / P_{c, t+1}}{\Lambda_{c, t} / P_{c, t}} B_{t+1}(i)\right]=B_{t}(i)+\left(1+\varsigma_{\theta, w}\right) W_{t}(i) L_{y, t}(i)+\operatorname{Profits}_{t}(i)-\operatorname{Taxes}_{t}(i)-P_{t} C_{t}(i)$, $L_{y, t}(i)=L_{u, t}(i)-\frac{\chi_{w}}{2}\left(\frac{W_{t}(i)}{W_{t-1}(i)}-\left(1-\gamma_{w}\right) \Pi_{w, *}-\gamma_{w} \Pi_{w, t-1}\right)^{2} L_{u, t}$, and

$L_{y, t}(i)=\left(\frac{W_{t}(i)}{W_{t}}\right)^{-\Theta_{w, t}} \int_{0}^{1} L_{y, t}(i, j) d j$.

The parameter $\varsigma_{\theta, w}$ in the household's budget constraint is a subsidy (equal to $\left.\left(\Theta_{w, *}-1\right)^{-1}\right)$, which ensures that in the absence of nominal rigidities the model's equilibrium outcome is Pareto optimal. The variable $B_{t}(i)$ in the budget constraint is the state-contingent value, in terms of the numeraire, of household $i$ 's asset holdings at the beginning of period $t$. We assume that there exists a risk-free one-period bond, which pays one unit of the numeraire in each state, and denote its yield - that is, the gross nominal interest rate between periods $t$ and $t+1$ - by $R_{t} \equiv\left(E_{t} \beta \frac{\Lambda_{c, t+1} / P_{t+1}}{\Lambda_{c, t} / P_{t}}\right)^{-1}$. Profits in the budget constraint are those rebated from firms, which are ultimately owned by households. Taxes in the budget constraint are lumpsum and are raised by the fiscal authority (which operates in the background of our model) solely to finance the subsidies on labor supply and production, which ensure the Pareto optimality of the steady-state outcome; specifically, $\int_{0}^{1} \operatorname{Taxes}_{t}(i) d i=\varsigma_{\theta, w} \int_{0}^{1} W_{t}(i) L_{y, t}(i) d i+\varsigma_{\theta, p} \int_{0}^{1} P_{t}(j) Y_{y, t}(j) d j$ 


\section{A.2 First-order conditions}

The first-order conditions from the intermediate goods producing firms' cost-minimization problem (equation 12), the labor demand curve and marginal cost function, are:

$$
\begin{aligned}
L_{y, t} & =\frac{Y_{m, t}}{A_{t}} \\
\frac{M C_{t}}{P_{t}} & =\frac{W_{t}}{P_{t}} \cdot \frac{1}{A_{t}}
\end{aligned}
$$

The first-order condition from the intermediate goods producing firms profit-maximization problem (equation 13), the aggregate supply curver, is:

$$
\begin{aligned}
\Theta_{p, t} \cdot \frac{M C_{t}}{P_{t}} \cdot Y_{f, t} & =\left(\Theta_{p, t}-1\right)\left(1+\varsigma_{\theta, p}\right) Y_{f, t}+\chi_{p}\left(\Pi_{p, t}-\gamma_{p} \Pi_{p, t-1}-\left(1-\gamma_{p}\right) \Pi_{p, *}\right) \Pi_{p, t} \cdot \frac{M C_{t}}{P_{t}} \cdot Y_{m, t} \\
& -\beta E_{t}\left[\frac{\Lambda_{c, t+1}}{\Lambda_{c, t}} \cdot \chi_{p}\left(\Pi_{p, t+1}-\gamma_{p} \Pi_{p, t}-\left(1-\gamma_{p}\right) \Pi_{p, *}\right) \Pi_{p, t+1} \cdot \frac{M C_{t+1}}{P_{t+1}} \cdot Y_{m, t+1}\right]
\end{aligned}
$$

The first-order conditions from the household's utility-maximization problem (equation 14), the Euler equation and the labor supply curve, are:

$$
\begin{aligned}
\frac{\Lambda_{c, t}}{P_{t}} & =\beta R_{t} E_{t}\left[\frac{\Lambda_{c, t+1}}{P_{t+1}}\right] \\
\Theta_{w, t} \cdot \frac{\Lambda_{l, t}}{\Lambda_{c, t}} \cdot L_{y, t} & =\left(\Theta_{w, t}-1\right)\left(1+\varsigma_{\theta, w}\right) \frac{W_{t}}{P_{t}} \cdot L_{y, t}+\chi_{w}\left(\Pi_{w, t}-\gamma_{w} \Pi_{w, t-1}-\left(1-\gamma_{w}\right) \Pi_{w, *}\right) \Pi_{w, t} \cdot \frac{\Lambda_{l, t}}{\Lambda_{c, t}} \cdot L_{u, t} \\
& -\beta E_{t}\left[\frac{\Lambda_{c, t+1}}{\Lambda_{c, t}} \cdot \chi_{w}\left(\Pi_{w, t+1}-\gamma_{w} \Pi_{w, t}-\left(1-\gamma_{w}\right) \Pi_{w, *}\right) \Pi_{w, t+1} \cdot \frac{\Lambda_{l, t+1}}{\Lambda_{c, t+1}} \cdot L_{u, t+1}\right]
\end{aligned}
$$

where

$$
\begin{aligned}
\Lambda_{c, t} & =\Xi_{c, t}\left(C_{t}-\eta C_{t-1}\right)^{-\sigma}\left(\bar{L}-L_{t}\right)^{\zeta(1-\sigma)}-E_{t} \beta \eta\left[\Xi_{c, t+1}\left(C_{t+1}-\eta C_{t}\right)^{-\sigma}\left(\bar{L}-L_{t+1}\right)^{\zeta(1-\sigma)}\right] \\
\Lambda_{l, t} & =\zeta \Xi_{c, t}\left(C_{t}-\eta C_{t-1}\right)^{(1-\sigma)}\left(\bar{L}-L_{t}\right)^{\zeta(1-\sigma)-1} .
\end{aligned}
$$

The model has three market clearing conditions: the labor market clearing condition, the intermediate-goods market clearing condition, and the final-goods market clearing condition. In the symmetric equilibrium these are given by:

$$
\begin{aligned}
L_{u, t} & =L_{y, t}+\frac{\chi_{w}}{2}\left(\Pi_{w, t}-\left(1-\gamma_{w}\right) \Pi_{w, *}-\gamma_{w} \Pi_{w, t-1}\right)^{2} L_{u, t}, \\
Y_{f, t} & =Y_{m, t}-\frac{\chi_{p}}{2}\left(\Pi_{p, t}-\left(1-\gamma_{p}\right) \Pi_{p, *}-\gamma_{p} \Pi_{p, t-1}\right)^{2} Y_{m, t}, \\
C_{t} & =Y_{f, t}
\end{aligned}
$$




\section{A.3 Log-linearized first-order conditions}

The first-order conditions implied by the intermediate goods producing firm's cost minimization problem, given by equations (15) and (16), log-linearize to

$$
\begin{aligned}
l_{y, t} & =y_{m, t}-a_{t} \\
m c_{t} & =w_{t}-a_{t}
\end{aligned}
$$

The first-order conditions implied by the intermediate goods producing firm's profit maximization problem, given by equation (17), log-linearizes to

$$
\begin{aligned}
\pi_{p, t}=\frac{\gamma_{p}}{1+\beta \gamma_{p}} \cdot \pi_{p, t-1} & +\frac{\beta}{1+\beta \gamma_{p}} \cdot E_{t} \pi_{p, t+1} \\
& +\frac{1}{1+\beta \gamma_{p}} \cdot \frac{\left(\Theta_{p, *}-1\right)\left(1+\varsigma_{\theta, p}\right)}{\Pi_{p, *}^{2} \chi_{p}}\left(m c_{t}-\frac{1}{\Theta_{p, *}-1} \cdot \theta_{p, t}\right) \\
= & \frac{\gamma_{p}}{1+\beta \gamma_{p}} \cdot \pi_{p, t-1}+\frac{\beta}{1+\beta \gamma_{p}} \cdot E_{t} \pi_{p, t+1}+\frac{1}{1+\beta \gamma_{p}} \cdot \kappa_{p}\left(m c_{t}-\frac{1}{\Theta_{p, *}-1} \cdot \theta_{p, t}\right)
\end{aligned}
$$

The first-order conditions implied by the household's utility maximization problem, given by equations (18) and (19), log-linearize to

$$
\begin{aligned}
\lambda_{c, t}= & r_{t}-E_{t} \pi_{p, t+1}+E_{t} \lambda_{c, t+1} \\
\pi_{w, t}=\frac{\gamma_{p}}{1+\beta \gamma_{p}} \cdot \pi_{p, t-1} & +\frac{\beta}{1+\beta \gamma_{w}} \cdot E_{t} \pi_{w, t+1} \\
& \quad+\frac{1}{1+\beta \gamma_{w}} \cdot \frac{\left(\Theta_{w, *}-1\right)\left(1+\varsigma_{\theta, w}\right)}{\Pi_{w, *}^{2} \chi_{w}} \cdot\left(\lambda_{l, t}-\lambda_{c, t}-w_{t}-\frac{1}{\Theta_{w, *}-1} \cdot \theta_{w, t}\right) \\
=\frac{\gamma_{p}}{1+\beta \gamma_{p}} \cdot \pi_{p, t-1} & +\frac{\beta}{1+\beta \gamma_{w}} \cdot E_{t} \pi_{w, t+1} \\
& \quad+\frac{1}{1+\beta \gamma_{w}} \cdot \kappa_{w} \cdot\left(\lambda_{l, t}-\lambda_{c, t}-w_{t}-\frac{1}{\Theta_{w, *}-1} \cdot \theta_{w, t}\right)
\end{aligned}
$$

where

$$
\begin{aligned}
\lambda_{c, t}= & \frac{1}{1-\eta \beta}\left(\frac{-\sigma}{1-\eta}\left(c_{t}-\eta c_{t-1}\right)+\xi_{c, t}-\zeta(1-\sigma) \frac{L_{u, *}}{\bar{L}-L_{u, *}} \cdot l_{u, t}\right) \\
& \quad-\frac{\eta \beta}{1-\eta \beta}\left(\frac{-\sigma}{1-\eta}\left(E_{t} c_{t+1}-\eta c_{t}\right)+E_{t} \xi_{c, t+1}-\zeta(1-\sigma) \frac{L_{u, *}}{\bar{L}-L_{u, *}} \cdot E_{t} l_{u, t+1}\right) \\
\lambda_{l, t}= & \frac{1-\sigma}{1-\eta}\left(c_{t}-\eta c_{t-1}\right)+\xi_{c, t}+(1-\zeta(1-\sigma)) \frac{L_{u, *}}{\bar{L}-L_{u, *}} \cdot l_{u, t} .
\end{aligned}
$$

The price markup shock $\theta_{p, t}$ in (27), the wage markup shock $\theta_{w, t}$ in (29), and the preference shock $\xi_{c, t}$ in (30) and (31) are as usual defined as the logs of their uppercase counterparts. 
The market clearing conditions, equations (22), (23), and (24), log-linearize to:

$$
\begin{gathered}
l_{u, t}=l_{y, t}=l_{t} \\
y_{f, t}=y_{m, t}=y_{t} \\
c_{t}=y_{f, t}
\end{gathered}
$$

Three more equations remain in our model: (i) the process for the shocks $A_{t}$, defined in equation (4), which log-linearizes to

$$
a_{t}=a_{t-1}+\epsilon_{t},
$$

(ii) the monetary policy process, which was already given in log-linearized form in equation (7), and (iii) an identity between price and wage inflation and real wages

$$
\frac{W_{t}}{P_{t}} \cdot \frac{P_{t-1}}{W_{t-1}}=\frac{W_{t}}{W_{t-1}} \cdot \frac{P_{t-1}}{P_{t}}=\frac{\Pi_{w, t}}{\Pi_{p, t}}
$$

which log-linearizes to

$$
w_{t}-w_{t-1}=\pi_{w, t}-\pi_{p, t}
$$

Before concluding this section we note the following about the steady-state solution to the model. We know from equations (16), (17), (19), (20), and (21) that in the steady state:

$$
1=\frac{M C_{*}}{P_{*}}=\frac{W_{*}}{P_{*}}=\frac{\Lambda_{l, *}}{\Lambda_{c, *}}=\frac{1-\eta}{1-\eta \beta} \cdot \frac{\zeta L_{u, *}}{\bar{L}-L_{u, *}}
$$

Since $L_{*}=L_{u, *}=L_{y, *}$ we can re-write this as:

$$
\frac{\zeta L_{*}}{\bar{L}-L_{*}}=\frac{1-\eta \beta}{1-\eta} .
$$

This means that we can re-write equations (30) and (31) as:

$$
\begin{aligned}
\lambda_{c, t}= & \frac{1}{1-\eta \beta}\left(\frac{-\sigma}{1-\eta}\left(c_{t}-\eta c_{t-1}\right)+\xi_{c, t}-(1-\sigma) \frac{1-\eta \beta}{1-\eta} \cdot l_{u, t}\right) \\
& +\frac{\eta \beta}{1-\eta \beta}\left(\frac{-\sigma}{1-\eta}\left(E_{t} c_{t+1}-\eta c_{t}\right)+E_{t} \xi_{c, t+1}-(1-\sigma) \frac{1-\eta \beta}{1-\eta} \cdot E_{t} l_{u, t+1}\right) \\
\lambda_{l, t}= & \frac{1-\sigma}{1-\eta}\left(c_{t}-\eta c_{t-1}\right)+\xi_{c, t}+\frac{1-\zeta(1-\sigma)}{\zeta} \cdot \frac{1-\eta \beta}{1-\eta} \cdot l_{u, t} .
\end{aligned}
$$

Since $l_{u, t}=l_{y, t}=y_{m, t}-a_{t}=y_{t}-a_{t}$ and $c_{t}=y_{f, t}=y_{t}$

$$
\begin{aligned}
\lambda_{c, t}= & \frac{1}{1-\eta \beta}\left(\frac{-\sigma}{1-\eta}\left(y_{t}-\eta y_{t-1}\right)+\xi_{c, t}-(1-\sigma) \frac{1-\eta \beta}{1-\eta}\left(y_{t}-a_{t}\right)\right) \\
& \quad+\frac{\eta \beta}{1-\eta \beta}\left(\frac{-\sigma}{1-\eta}\left(E_{t} y_{t+1}-\eta y_{t}\right)+E_{t} \xi_{c, t+1}-(1-\sigma) \frac{1-\eta \beta}{1-\eta}\left(E_{t} y_{t+1}-E_{t} a_{t+1}\right)\right) \\
\lambda_{l, t}= & \frac{1-\sigma}{1-\eta}\left(y_{t}-\eta y_{t-1}\right)+\xi_{c, t}+\frac{1-\zeta(1-\sigma)}{\zeta} \cdot \frac{1-\eta \beta}{1-\eta}\left(y_{t}-a_{t}\right) .
\end{aligned}
$$

Equations (37) and (38) will be used in deriving the natural rate. 


\section{A.4 Natural rates in the log-linear model}

The natural rate of output, i.e. the level of output in the equilibrium with perfectly flexible prices and wages, is determined by the condition that the marginal rate of substitution between consumption and leisure be (up to constants) equal to the marginal product of labor at all dates $t$. In $\log$ terms, $\tilde{y}_{t}$ is determined implicitly by the equation

$$
m r s_{t}=m p l_{t}
$$

where $m r s_{t}=\lambda_{l, t}-\lambda_{c, t}$ and, from the production function (3), $m p l_{t}=a_{t}$. Substituting from (37) and (38) for $\lambda_{c, t}$ and $\lambda_{l, t}$ yields the following expression for $\tilde{y}_{t}$ :

$$
\left[\delta_{1}-\delta_{2}\left(L+\beta L^{-1}\right)\right] \tilde{y}_{t}=\left[\delta_{3}-\delta_{4} L^{-1}\right] a_{t}+\delta_{5}\left[1-L^{-1}\right] \xi_{c, t}
$$

where $L$ denotes the lag operator, $L^{-1} x_{t} \equiv E_{t} x_{t+1}$, and

$$
\begin{aligned}
\delta_{1} & =\frac{2(1-\sigma)}{1-\eta}+\frac{1-\zeta(1-\sigma)}{\zeta} \frac{1-\beta \eta}{1-\eta}+\frac{\sigma\left(1+\beta \eta^{2}\right)}{(1-\beta \eta)(1-\eta)} \\
\delta_{2} & =\eta\left[\frac{1-\sigma}{1-\eta}+\frac{\sigma}{(1-\beta \eta)(1-\eta)}\right] \\
\delta_{3} & =1+\frac{1-\zeta(1-\sigma)}{\zeta} \frac{1-\beta \eta}{1-\eta}+\frac{1-\sigma}{1-\eta} \\
\delta_{4} & =\frac{\beta \eta(1-\sigma)}{1-\eta}, \text { and } \delta_{5}=\frac{\beta \eta}{1-\beta \eta}
\end{aligned}
$$

The natural rate of interest, denoted $\tilde{r}_{t}$, is the real rate $r_{t}-E_{t} \pi_{t+1}$ prevailing in the equilibrium with perfectly flexible prices and wages. Letting $\tilde{\lambda}_{c, t}$ denote the expression (37) with $\tilde{y}_{t}$ substituted for $y_{t}$, the Euler equation (28) in this equilibrium can be expressed as

$$
\tilde{r}_{t}=\tilde{\lambda}_{c, t}-E_{t} \tilde{\lambda}_{c, t+1}
$$

But, in this equilibrium, $\tilde{\lambda}_{c, t}=\tilde{\lambda}_{l, t}-a_{t}$. Substituting for $\tilde{\lambda}_{c, t}$ we obtain

$$
\begin{aligned}
\tilde{r}_{t} & =\left[\delta_{6}+\delta_{7}-\delta_{6} L-\delta_{7} L^{-1}\right] \tilde{y}_{t}+\delta_{8}\left[L^{-1}-1\right] a_{t}+\left[1-L^{-1}\right] \xi_{c, t} \\
& =\delta_{6} \Delta \tilde{y}_{t}-\delta_{7} E_{t} \Delta \tilde{y}_{t+1}+\delta_{8} E_{t} \Delta a_{t+1}+E_{t} \Delta \xi_{t+1}^{c}
\end{aligned}
$$

with

$$
\begin{aligned}
\delta_{6} & =\frac{\eta(1-\sigma)}{1-\eta} \\
\delta_{7} & =\frac{1-\sigma}{1-\eta}+\frac{1-\zeta(1-\sigma)}{\zeta} \frac{1-\beta \eta}{1-\eta} \\
\delta_{8} & =1+\frac{1-\zeta(1-\sigma)}{\zeta} \frac{1-\beta \eta}{1-\eta}
\end{aligned}
$$




\section{B VAR Identification and Structural Shocks}

As discussed in section 3, we are using one long-run and one short-run restriction to identify two elements of the vector of shocks $\varepsilon_{t}$ in (9). In order to estimate the VAR in structural form, we need a further set of assumptions to just-identify the elements of $A_{0}$. We follow Altig et al. (2002) by assuming that the submatrix consisting of columns 2-4 and rows 2-4 of $A_{0}$ is lower triangular. This assumption is without loss of generality as we do not attach any structural interpretation to elements 2 through 4 of $\varepsilon_{t}$. With these assumptions, we estimate the first equation of the structural VAR imposing the long-run restrictions in the manner of Shapiro and Watson (1988) by including contemporaneous and lagged variables of elements 2 through 4 of $Y_{t}$ in first-differenced form. To control for simultaneity, we

estimate the equation by $2 \mathrm{SLS}$, using a constant and $Y_{t-1}, \ldots, Y_{t-4}$ as first-stage regressors for elements 2 through 4 of $Y_{t}$. We then sequentially estimate equations 2 through 4 by IV, using the residuals from the previous regressions as instruments for contemporaneous variables. Equation 5 can be estimated by OLS by virtue of our short-run identifying assumption.

We modify this identification strategy in one respect. Because, in contrast to Altig et al., our VAR includes hours per capita in first differences, we would like to assure that the longrun response of hours to a technology shock is zero, consistent with the observation that hours worked have remained broadly unchanged despite the secular trend in real wages. When this second long-run restriction is not imposed, the IRF of $\Delta l$ usually does not integrate to zero. We therefore reorder our vector of endogenous variables to include $\Delta l$ as the second variable, and apply the Shapiro-Watson method to the first two equations. This leaves the interpretation of the first element of $\varepsilon_{t}$ unchanged, but the second element is now the only shock that permanently affects hours per capita. Contrary to the findings reported by Francis and Ramey (2005), Laubach and Williams (2006) find that imposing this second long-run restriction can have a substantial effect on the response of hours to a technology shock.

To compute the historical processes of the remaining three structural shocks $\xi_{c, t}, \theta_{p, t}$, and $\theta_{w, t}$, we invert the model at our parameter estimates to find the time series for these processes that would allow us to exactly replicate the historical data used in estimation. In fact, this method does not work exactly because the absence of capital in our model implies that the innovation to technology $\epsilon_{t}$ is identical to the first difference of log output per hour 
$\Delta\left(y_{t}-l_{t}\right)$, which is close to, but not exactly true in the data. In constructing the shock processes, we therefore replace the log hours data with detrended log output minus the cumulative sum of the identified technology shock. This replacement also means that the simulated policy rule, which now responds to this model-consistent hours measure, does not excatly replicate the historical funds rate series, which is consistent with policy responding to log hours, but the correlation between the two funds rate series is 0.85 . The resulting shock processes are serially correlated, and in the model simulations we approximate them as $\mathrm{AR}(1)$ processes with coefficients $0.41,0.67$, and 0.57 respectively.

\section{Deriving the Welfare Criterion}

To derive the welfare criterion we first take a second-order approximation to the withinperiod utility function

$$
\begin{aligned}
\frac{1}{1-\sigma} & \cdot \frac{\Xi_{c, t}\left(C_{t}-\eta C_{t-1}\right)^{1-\sigma}\left(\bar{L}-L_{u, t}\right)^{\zeta(1-\sigma)}}{\left(C_{*}-\eta C_{*}\right)^{1-\sigma}\left(\bar{L}-L_{u, *}\right)^{\zeta(1-\sigma)}} \\
& =\text { T.I.P. } \\
& +\frac{1}{1-\eta}\left(c_{t}+\frac{1}{2} \cdot c_{t}^{2}\right)+\frac{-\eta}{1-\eta}\left(c_{t-1}+\frac{1}{2} \cdot c_{t-1}^{2}\right)-\frac{\zeta L_{u, *}}{\bar{L}-L_{u, *}}\left(l_{u, t}+\frac{1}{2} \cdot l_{u, t}^{2}\right) \\
& +\frac{1}{2}(-\sigma) \frac{1}{1-\eta} \cdot \frac{1}{1-\eta}\left(c_{t}+\frac{1}{2} \cdot c_{t}^{2}\right)\left(c_{t}+\frac{1}{2} \cdot c_{t}^{2}\right) \\
& +\frac{1}{2}(-\sigma) \frac{-\eta}{1-\eta} \cdot \frac{-\eta}{1-\eta}\left(c_{t-1}+\frac{1}{2} \cdot c_{t-1}^{2}\right)\left(c_{t-1}+\frac{1}{2} \cdot c_{t-1}^{2}\right) \\
& -\frac{1}{2} \cdot \frac{1-\zeta(1-\sigma)}{\zeta} \frac{\zeta L_{u, *}}{\bar{L}-L_{u, *}} \cdot \frac{\zeta L_{u, *}}{\bar{L}-L_{u, *}}\left(l_{u, t}+\frac{1}{2} \cdot l_{u, t}^{2}\right)\left(l_{u, t}+\frac{1}{2} \cdot l_{u, t}^{2}\right) \\
& +(-\sigma) \frac{1}{1-\eta} \cdot \frac{-\eta}{1-\eta}\left(c_{t}+\frac{1}{2} \cdot c_{t}^{2}\right)\left(c_{t-1}+\frac{1}{2} \cdot c_{t-1}^{2}\right) \\
& -(1-\sigma) \frac{1}{1-\eta} \cdot \frac{\zeta L_{u, *}}{\bar{L}-L_{u, *}}\left(c_{t}+\frac{1}{2} \cdot c_{t}^{2}\right)\left(l_{u, t}+\frac{1}{2} \cdot l_{u, t}^{2}\right) \\
& -(1-\sigma) \frac{-\eta}{1-\eta} \cdot \frac{\zeta L_{u, *}}{\bar{L}-L_{u, *}}\left(c_{t-1}+\frac{1}{2} \cdot c_{t-1}^{2}\right)\left(l_{u, t}+\frac{1}{2} \cdot l_{u, t}^{2}\right) \\
& +\frac{1}{1-\eta}\left(c_{t}+\frac{1}{2} \cdot c_{t}^{2}\right)\left(\xi_{c, t}+\frac{1}{2} \cdot \xi_{c, t}^{2}\right)+\frac{-\eta}{1-\eta}\left(c_{t-1}+\frac{1}{2} \cdot c_{t-1}^{2}\right)\left(\xi_{c, t}+\frac{1}{2} \cdot \xi_{c, t}^{2}\right) \\
& -\frac{\zeta L_{u, *}}{\bar{L}-L_{u, *}}\left(l_{u, t}+\frac{1}{2} \cdot l_{u, t}^{2}\right)\left(\xi_{c, t}+\frac{1}{2} \cdot \xi_{c, t}^{2}\right)
\end{aligned}
$$

We also make use of the quadratic approximations to the labor demand curve (equation 15) and the market clearing conditions (equations 23, 22, and 24) which are given by:

$$
\left(l_{y, t}+\frac{1}{2} \cdot l_{y, t}^{2}\right)=\left(y_{m, t}+\frac{1}{2} \cdot y_{m, t}^{2}\right)-\left(a_{t}+\frac{1}{2} \cdot a_{t}^{2}\right)-y_{m, t} a_{t}
$$




$$
\begin{aligned}
\left(l_{y, t}+\frac{1}{2} \cdot l_{y, t}^{2}\right) & =\left(l_{u, t}+\frac{1}{2} \cdot l_{u, t}^{2}\right)-\frac{1}{2} \cdot \chi_{w} \cdot \Pi_{w, *}^{2}\left(\pi_{w, t}^{2}+\gamma_{w}^{2} \cdot \pi_{w, t-1}^{2}-2 \cdot \gamma_{w} \cdot \pi_{w, t} \pi_{w, t-1}\right) \\
\left(y_{f, t}+\frac{1}{2} \cdot y_{f, t}^{2}\right) & =\left(y_{m, t}+\frac{1}{2} \cdot y_{m, t}^{2}\right)-\frac{1}{2} \cdot \chi_{p} \cdot \Pi_{p, *}^{2}\left(\pi_{p, t}^{2}+\gamma_{p}^{2} \cdot \pi_{p, t-1}^{2}-2 \cdot \gamma_{p} \cdot \pi_{p, t} \pi_{p, t-1}\right) \\
\left(c_{t}+\frac{1}{2} \cdot c_{t}^{2}\right) & =\left(y_{f, t}+\frac{1}{2} \cdot y_{f, t}^{2}\right)
\end{aligned}
$$

Substituting the above equations into the equation (43) and making a number of substitutions yields:

$$
\begin{aligned}
\frac{1}{1-\sigma} & \cdot \frac{\Xi_{c, t}\left(C_{t}-\eta C_{t-1}\right)^{1-\sigma}\left(\bar{L}-L_{u, t}\right)^{\zeta(1-\sigma)}}{\left(C_{*}-\eta C_{*}\right)^{1-\sigma}\left(\bar{L}-L_{u, *}\right)^{\zeta(1-\sigma)}} \\
& =\text { T.I.P. } \\
& -\frac{1}{2} \cdot \sigma\left(\frac{1}{1-\eta}\right)^{2}\left(\left(y_{t}-\widetilde{y}_{t}\right)-\eta\left(y_{t-1}-\widetilde{y}_{t-1}\right)\right)^{2} \\
& -\frac{1}{2} \cdot \frac{1-\zeta(1-\sigma)}{\zeta} \cdot\left(\frac{1-\beta \eta}{1-\eta}\right)^{2}\left(y_{t}-\widetilde{y}_{t}\right)^{2} \\
& -(1-\sigma) \cdot \frac{1-\beta \eta}{1-\eta} \cdot \frac{1}{1-\eta} \cdot\left(y_{t}-\widetilde{y}_{t}\right)\left(\left(y_{t}-\widetilde{y}_{t}\right)-\eta\left(y_{t-1}-\widetilde{y}_{t-1}\right)\right) \\
& -\frac{1}{2} \cdot \frac{1-\beta \eta}{1-\eta}\left\{\chi_{p} \Pi_{p, *}^{2} \cdot\left(\pi_{p, t}-\gamma_{p} \pi_{p, t-1}\right)^{2}+\chi_{w} \Pi_{w, *}^{2} \cdot\left(\pi_{w, t}-\gamma_{w} \pi_{w, t-1}\right)^{2}\right\} .
\end{aligned}
$$

This can also be written as:

$$
\begin{aligned}
\frac{1}{1-\sigma} & \cdot \frac{\Xi_{c, t}\left(C_{t}-\eta C_{t-1}\right)^{1-\sigma}\left(\bar{L}-L_{u, t}\right)^{\zeta(1-\sigma)}}{\left(C_{*}-\eta C_{*}\right)^{1-\sigma}\left(\bar{L}-L_{u, *}\right)^{\zeta(1-\sigma)}} \\
& =\text { T.I.P. } \\
& -\frac{1}{2} \cdot \sigma\left(\frac{1}{1-\eta}\right)^{2}\left(\left(y_{t}-\widetilde{y}_{t}\right)-\eta\left(y_{t-1}-\widetilde{y}_{t-1}\right)\right)^{2} \\
& -\frac{1}{2} \cdot \frac{1-\zeta(1-\sigma)}{\zeta} \cdot\left(\frac{1-\beta \eta}{1-\eta}\right)^{2}\left(y_{t}-\widetilde{y}_{t}\right)^{2} \\
& -(1-\sigma) \cdot \frac{1-\beta \eta}{1-\eta} \cdot \frac{1}{1-\eta} \cdot\left(y_{t}-\widetilde{y}_{t}\right)\left(\left(y_{t}-\widetilde{y}_{t}\right)-\eta\left(y_{t-1}-\widetilde{y}_{t-1}\right)\right) \\
& -\frac{1}{2} \cdot \frac{1-\beta \eta}{1-\eta}\left\{\frac{\Theta_{p, *}}{\kappa_{r, p}} \cdot\left(\pi_{p, t}-\gamma_{p} \pi_{p, t-1}\right)^{2}+\frac{\Theta_{w, *}}{\kappa_{r, w}} \cdot\left(\pi_{w, t}-\gamma_{w} \pi_{w, t-1}\right)^{2}\right\},
\end{aligned}
$$

which is the equation given in section 4 of the paper.

\section{The Model's Calvo Counterpart}

As noted in section 2.3 of the paper we preferred to use the quadratic adjustment cost approach to modeling sticky-prices and sticky-wages in preference to alternatives that imply 
heterogeneity among agents. Naturally, this raises the question of whether this modelling choice has serious implications for our results.

In this appendix we present our model's Calvo counterpart. Clearly the principal differences are that we no longer have the price and wage adjustment cost terms in equations 2 and 6 (so that these equations become simply $Y_{f, t}(j)=Y_{m, t}(j)$ and $L_{u, t}(i)=L_{y, t}(i)$ ); instead, however, the model contains Calvo reset probabilities in the firms' profit-maximization problem and the households' utility maximization problems. All of the parts of the modelthat is, the firms' cost-minimization problem and the process describing monetary policyremain the same.

Under Calvo pricing-setting the firm's profit-maximization problem is:

$$
\begin{aligned}
\max _{\left\{P_{t}(j)\right\}_{t=0}^{\infty}}\{ & \left.\left(1+\varsigma_{\theta}\right) Y_{f, 0}(j) P_{0}(j)-Y_{m, 0}(j) M C_{0}(j)\right\} \\
& +E_{0} \sum_{t=1}^{\infty}\left(\beta \alpha_{p}\right)^{t} \frac{\Lambda_{c, t}}{P_{t}}\left\{\left(1+\varsigma_{\theta, p}\right) Y_{f, t}(j) P_{t}(j)\left(\left(\Pi_{p, *}^{t}\right)^{1-\gamma_{c, p}} \prod_{l=0}^{t} \Pi_{p, l}^{\gamma_{c, p}}\right)-Y_{m, t}(j) M C_{t}(j)\right\} \\
& \text { subject to } Y_{f, t}(j)=Y_{m, t}(j) \text { and } Y_{f, t}(j)=\left(P_{t}(j) / P_{t}\right)^{-\Theta_{p, t}} Y_{f, t} .
\end{aligned}
$$

Under Calvo wage-setting the household's utility-maximization problem is:

$$
\max _{\left\{C_{t}(i), W_{t}(i)\right\}_{t=0}^{\infty}} E_{0} \frac{1}{1-\sigma} \sum_{t=0}^{\infty} \beta^{t}\left[\left(C_{t}(i)-\eta C_{t-1}(i)\right)\left(\bar{L}-L_{u, t}(i)\right)^{\zeta}\right]^{1-\sigma}
$$

subject to

$$
\begin{aligned}
& E_{0}\left[\beta \frac{\Lambda_{c, 1} / P_{c, 1}}{\Lambda_{c, 0} / P_{c, 0}} B_{1}(i)\right]=B_{0}(i)+\left(1+\varsigma_{\theta, w}\right) L_{y, 0}(i) W_{0}(i)+\operatorname{Profits}_{0}(i)-P_{0} C_{0}(i), \\
& \begin{aligned}
E_{t}\left[\beta \frac{\Lambda_{c, t+1} / P_{c, t+1}}{\Lambda_{c, t} / P_{c, t}} B_{t+1}(i)\right] & =B_{t}(i)+\left(1+\varsigma_{\theta, w}\right) L_{y, t}(i) W_{t}(i)\left(\alpha_{w}\right)^{t}\left(\left(\Pi_{w, *}^{t}\right)^{1-\gamma_{c, w}} \prod_{l=0}^{t} \Pi_{w, l}^{\gamma_{c, w}}\right) \\
& +\operatorname{Profits}_{t}(i)-P_{t} C_{t}(i), \quad \text { for } t=1, \cdots, \infty .
\end{aligned} \\
& L_{y, t}(i)=L_{u, t}(i) \text { and } L_{y, t}(i)=\left(W_{t}(i) / W_{t}\right)^{-\Theta_{w, t}} \int_{0}^{1} L_{y, t}(i, j) d j .
\end{aligned}
$$

All of the equations in the log-linearized model other than the price and wage Phillips curves are unaltered by our assumption for price- and wage- setting. Equations (27) and (29) are however replaced by:

$$
\begin{aligned}
\pi_{p, t} & =\frac{\gamma_{c, p}}{1+\beta \gamma_{c, p}} \cdot \pi_{p, t-1}+\frac{\beta}{1+\beta \gamma_{c, p}} \cdot E_{t} \pi_{p, t+1} \\
& +\frac{1}{1+\beta \gamma_{c, p}} \cdot \frac{\left(1-\alpha_{p}\right)\left(1-\beta \alpha_{p}\right)}{\alpha_{p}}\left(m c_{t}-\frac{1}{\Theta_{p, *}-1} \cdot \theta_{p, t}\right)
\end{aligned}
$$




$$
\begin{aligned}
\pi_{w, t}= & \frac{\gamma_{c, w}}{1+\beta \gamma_{c, w}} \cdot \pi_{w, t-1}+\frac{\beta}{1+\beta \gamma_{c, w}} \cdot E_{t} \pi_{w, t+1} \\
+ & \frac{1}{1+\beta \gamma_{c, w}} \cdot \frac{\left(1-\alpha_{w}\right)\left(1-\beta \alpha_{w}\right)}{\alpha_{w}} \\
& \quad \times\left(1+\Theta_{w, *} \cdot \frac{1-\zeta(1-\sigma)}{\zeta} \cdot \frac{1-\beta \eta}{1-\eta}\right)^{-1}\left(\lambda_{l, t}-\lambda_{c, t}-w_{t}-\frac{1}{\Theta_{w, *}-1} \cdot \theta_{w, t}\right)
\end{aligned}
$$

In estimating our model, we could have set:

$$
\kappa_{c, p}=\frac{\left(1-\alpha_{p}\right)\left(1-\beta \alpha_{p}\right)}{\alpha_{p}} \text { and } \kappa_{c, w}=\frac{\left(1-\alpha_{w}\right)\left(1-\beta \alpha_{w}\right)}{\alpha_{w}}\left(1+\Theta_{w, *} \cdot \frac{1-\zeta(1-\sigma)}{\zeta} \cdot \frac{1-\beta \eta}{1-\eta}\right)^{-1}
$$

and included:

$$
\begin{aligned}
\pi_{p, t}=\frac{\gamma_{c, p}}{1+\beta \gamma_{c, p}} \cdot \pi_{p, t-1} & +\frac{\beta}{1+\beta \gamma_{c, p}} \cdot E_{t} \pi_{p, t+1}+\frac{1}{1+\beta \gamma_{c, p}} \cdot \kappa_{c, p}\left(m c_{t}-\frac{1}{\Theta_{p, *}-1} \cdot \theta_{p, t}\right) \\
\pi_{w, t}=\frac{\gamma_{c, w}}{1+\beta \gamma_{c, w}} \cdot \pi_{w, t-1} & +\frac{\beta}{1+\beta \gamma_{c, w}} \cdot E_{t} \pi_{w, t+1} \\
& +\frac{1}{1+\beta \gamma_{c, w}} \cdot \kappa_{c, w}\left(\lambda_{l, t}-\lambda_{c, t}-w_{t}-\frac{1}{\Theta_{w, *}-1} \cdot \theta_{w, t}\right)
\end{aligned}
$$

in our estimated model. These would have been identical to equations (27) and (29) which we did estimate.

Under Calvo pricing the loss function is:

$$
\begin{aligned}
& \frac{1}{1-\sigma} \cdot \frac{\left(C_{t}-\eta C_{t-1}\right)^{1-\sigma}\left(\bar{L}-L_{u, t}\right)^{\zeta(1-\sigma)}}{\left(C_{*}-\eta C_{*}\right)^{1-\sigma}\left(\bar{L}-L_{u, *}\right)^{\zeta(1-\sigma)}} \\
& =\text { T.I.P. } \\
& -\frac{1}{2} \cdot \sigma\left(\frac{1}{1-\eta}\right)^{2}\left(\left(y_{t}-\widetilde{y}_{t}\right)-\eta\left(y_{t-1}-\widetilde{y}_{t-1}\right)\right)^{2} \\
& -\frac{1}{2} \cdot \frac{1-\zeta(1-\sigma)}{\zeta} \cdot\left(\frac{1-\beta \eta}{1-\eta}\right)^{2}\left(y_{t}-\widetilde{y}_{t}\right)^{2} \\
& -(1-\sigma) \cdot \frac{1-\beta \eta}{1-\eta} \cdot \frac{1}{1-\eta} \cdot\left(y_{t}-\widetilde{y}_{t}\right)\left(\left(y_{t}-\widetilde{y}_{t}\right)-\eta\left(y_{t-1}-\widetilde{y}_{t-1}\right)\right) \\
& -\frac{1}{2} \cdot \frac{1-\beta \eta}{1-\eta} \cdot \Theta_{p, *} \cdot \frac{\alpha_{p}}{\left(1-\alpha_{p}\right)\left(1-\beta \alpha_{p}\right)} \cdot\left(\pi_{p, t}-\gamma_{p} \pi_{p, t-1}\right)^{2} \\
& -\frac{1}{2} \cdot \frac{1-\beta \eta}{1-\eta} \cdot \Theta_{w, *} \cdot \frac{\alpha_{w}}{\left(1-\alpha_{w}\right)\left(1-\beta \alpha_{w}\right)} \cdot\left(1+\Theta_{w, *} \cdot \frac{1-\zeta(1-\sigma)}{\zeta} \cdot \frac{1-\beta \eta}{1-\eta}\right)^{2}\left(\pi_{w, t}-\gamma_{w} \pi_{w, t-1}\right)^{2},
\end{aligned}
$$

This can also be written as:

$$
\begin{aligned}
& \frac{1}{1-\sigma} \cdot \frac{\left(C_{t}-\eta C_{t-1}\right)^{1-\sigma}\left(\bar{L}-L_{u, t}\right)^{\zeta(1-\sigma)}}{\left(C_{*}-\eta C_{*}\right)^{1-\sigma}\left(\bar{L}-L_{u, *}\right)^{\zeta(1-\sigma)}} \\
& \quad=\text { T.I.P. }
\end{aligned}
$$




$$
\begin{aligned}
& -\frac{1}{2} \cdot \sigma\left(\frac{1}{1-\eta}\right)^{2}\left(\left(y_{t}-\widetilde{y}_{t}\right)-\eta\left(y_{t-1}-\widetilde{y}_{t-1}\right)\right)^{2} \\
& -\frac{1}{2} \cdot \frac{1-\zeta(1-\sigma)}{\zeta} \cdot\left(\frac{1-\beta \eta}{1-\eta}\right)^{2}\left(y_{t}-\widetilde{y}_{t}\right)^{2} \\
& -(1-\sigma) \cdot \frac{1-\beta \eta}{1-\eta} \cdot \frac{1}{1-\eta} \cdot\left(y_{t}-\widetilde{y}_{t}\right)\left(\left(y_{t}-\widetilde{y}_{t}\right)-\eta\left(y_{t-1}-\widetilde{y}_{t-1}\right)\right) \\
& -\frac{1}{2} \cdot \frac{1-\beta \eta}{1-\eta} \cdot \frac{\Theta_{p, *}}{\kappa_{c, p}} \cdot\left(\pi_{p, t}-\gamma_{p} \pi_{p, t-1}\right)^{2} \\
& -\frac{1}{2} \cdot \frac{1-\beta \eta}{1-\eta} \cdot \frac{\Theta_{w, *}}{\kappa_{c, w}} \cdot \underbrace{\left(1+\Theta_{w, *} \cdot \frac{1-\zeta(1-\sigma)}{\zeta} \cdot \frac{1-\beta \eta}{1-\eta}\right)}_{*}\left(\pi_{w, t}-\gamma_{w} \pi_{w, t-1}\right)^{2},
\end{aligned}
$$

where the " $*$ " term is only term that differs from what appears in the loss funciton under our quadratic adjustment costs assumption. 